\title{
Intercomparison of Precipitation Estimates over the Arctic Ocean and Its Peripheral Seas from Reanalyses ${ }^{\mathscr{O}}$
}

\author{
LinetTe N. Boisvert AND MelindA A. Webster \\ Cryospheric Sciences Laboratory, NASA Goddard Space Flight Center, Greenbelt, Maryland
}

\begin{abstract}
Alek A. PetTy
Cryospheric Sciences Laboratory, NASA Goddard Space Flight Center, Greenbelt, and Earth System Science Interdisciplinary Center, University of Maryland, College Park, College Park, Maryland

THORSTEN MARKUS

Cryospheric Sciences Laboratory, NASA Goddard Space Flight Center, Greenbelt, Maryland

DAVID H. BROMWICH

Byrd Polar and Climate Research Center, The Ohio State University, Columbus, Ohio

RICHARD I. CULLATHER

Earth System Science Interdisciplinary Center, University of Maryland, College Park, College Park, and Global Modeling and Assimilation Office, NASA Goddard Space Flight Center, Greenbelt, Maryland
\end{abstract}

(Manuscript received 5 March 2018, in final form 19 July 2018)

\begin{abstract}
Precipitation over the Arctic Ocean has a significant impact on the basin-scale freshwater and energy budgets but is one of the most poorly constrained variables in atmospheric reanalyses. Precipitation controls the snow cover on sea ice, which impedes the exchange of energy between the ocean and atmosphere, inhibiting sea ice growth. Thus, accurate precipitation amounts are needed to inform sea ice modeling, especially for the production of thickness estimates from satellite altimetry freeboard data. However, obtaining a quantitative estimate of the precipitation distribution in the Arctic is notoriously difficult because of a number of factors, including a lack of reliable, long-term in situ observations; difficulties in remote sensing over sea ice; and model biases in temperature and moisture fields and associated uncertainty of modeled cloud microphysical processes in the polar regions. Here, we compare precipitation estimates over the Arctic Ocean from eight widely used atmospheric reanalyses over the period 2000-16 (nominally the "new Arctic"). We find that the magnitude, frequency, and phase of precipitation vary drastically, although interannual variability is similar. Reanalysis-derived precipitation does not increase with time as expected; however, an increasing trend of higher fractions of liquid precipitation (rainfall) is found. When compared with drifting ice mass balance buoys, three reanalyses (ERA-Interim, MERRA, and NCEP R2) produce realistic magnitudes and temporal agreement with observed precipitation events, while two products [MERRA, version 2 (MERRA-2), and CFSR] show large, implausible magnitudes in precipitation events. All the reanalyses tend to produce overly frequent Arctic precipitation. Future work needs to be undertaken to determine the specific factors in reanalyses that contribute to these discrepancies in the new Arctic.
\end{abstract}

Supplemental information related to this paper is available at the Journals Online website: https://doi.org/10.1175/JCLI-D-18-0125.s1.

Corresponding author: Linette Boisvert-McPartland, linette.n. boisvert@nasa.gov

\section{Introduction}

Precipitation onto the Arctic Ocean has a significant influence on the Arctic freshwater budget (e.g., Serreze et al. 1995; Cullather et al. 2000; Lique et al. 2016), ocean circulation (e.g., Hibler and Zhang 1995), surface 
energy budget, and the evolution of the sea ice cover throughout the year (e.g., Serreze and Hurst 2000). The magnitude of precipitation accumulating over the sea ice pack largely determines the depth of the snow layer, which modulates the rate of sea ice growth because of its highly insulating properties (Sturm et al. 2002). The phase of the precipitation falling on the sea ice pack is also important. As rain, it can instead melt, compact, and densify the snowpack, thus reducing the surface albedo and promoting sea ice melt (Perovich et al. 2002). Because of the importance of precipitation to the sea ice and Arctic system, it is therefore a critical climate variable to understand and utilize so that the current and future climate states can be reliably predicted. However, it remains one of the most uncertain variables in Arctic reanalyses.

Snow depth on sea ice is a primary source of uncertainty in deriving sea ice thickness from altimetry freeboard measurements (e.g., Giles et al. 2008), specifically those from ESA's current CryoSat-2 radar altimeter (Wingham et al. 2006) and NASA's Ice, Cloud, and Elevation Satellite-2 (ICESat-2) laser altimeter (Markus et al. 2017). The altimetry technique uses measurements of freeboard, the extension of sea ice and snow cover above the local sea level, and estimates of snow depth to derive sea ice thickness. Concurrent information on snow depth distributions throughout the year is therefore vital for producing accurate satellite estimates of sea ice thickness.

Since there are currently no seasonal basin-scale observations of snow on sea ice, snow depths are obtained by two commonly used approaches: 1 ) a historical snow climatology based on field observations (e.g., Warren climatology; Warren et al. 1999) and 2) modeling snow depths based on sea ice concentration, drift, and atmospheric forcing from reanalysis data (Kwok and Cunningham 2008; Maksym and Markus 2008). However, the historical climatology has been shown to be unrepresentative of the current snow depths in the western Arctic (Kurtz and Farrell 2011; Webster et al. 2014), and modeled snow depths are highly sensitive to the choice of reanalysis (Blanchard-Wrigglesworth et al. 2018), all of which warrants a more detailed assessment of the accuracies of the reanalyses currently available.

Reanalyses do not assimilate observations of precipitationinstead, this variable is predicted. Differences in precipitation are likely due to the complexity and difficulty of modeling precipitation processes in the atmosphere, including the representation of cloud microphysics, boundary layer processes, large-scale atmospheric circulations, and many other issues (Dai 2006). Unfortunately, these processes remain poorly understood, and the accuracy of these is not easily validated over the Arctic Ocean. Snow, representing the majority of the precipitation, is difficult to measure accurately because of undercatchment biases introduced by blowing and drifting snow and snowfall during windy conditions (Sevruk 1982; Yang et al. 1995; Goodison et al. 1998; Adam and Lettenmaier 2003; Serreze et al. 2005). Observations over sea ice are too sparse for quantifying the differences in gauge undercatchment between the sea ice and land environments; however, the two datasets that exist indicate that the snow water equivalent measured from snow on sea ice is generally higher than that measured by precipitation gauges, with one case study yielding a 25\% difference (Colony et al. 1998; Sturm et al. 2002). Other difficulties in measuring precipitation arise from rime ice formation, different types of gauges and their associated biases, how trace amounts of snow are measured and defined, and the logistical challenge in collecting long-duration data on a variable, mobile oceanic ice cover in the remote, harsh Arctic environment (Goodison et al. 1994, 15-20; Walsh et al. 1998). Because of these shortcomings, Arctic-wide precipitation is difficult to capture and reproduce accurately. Thus, precipitation in the Arctic is one of the variables with the largest uncertainty in seasonal forecasting and global climate model projections and should be used with great caution (Bosilovich et al. 2011; Trenberth et al. 2011).

To better understand the potential biases and uncertainties in precipitation derived from reanalyses over the Arctic Ocean, we compare precipitation data from eight reanalyses. We focus this analysis within the time period broadly defined as the "new Arctic": the Arctic climate regime since the early 2000s, when the sea ice cover has experienced an increased rate of decline in extent and thickness compared to the 1980-90s (e.g., Comiso et al. 2008; Kwok et al. 2009; Parkinson 2014; Lindsay and Schweiger 2015). In recent years, this new Arctic has become warmer and wetter (Boisvert and Stroeve 2015), and evaporation from the ice-free ocean has been increasing (Boisvert et al. 2015), all which likely affect the phase and frequency of precipitation. We seek to explore differences in precipitation from these reanalyses in terms of the amount, frequency, and phase, along with annual, seasonal, and regional differences. We use snow depth data collected from ice mass balance (IMB) buoys (Perovich et al. 2017) to assess discrepancies during observed precipitation events. The magnitudes and frequencies of these precipitation events will also be evaluated.

\section{Reanalyses}

The reanalyses considered here are regular gridded, retrospective descriptions of the atmosphere. Reanalyses 
TABLE 1. Descriptions of the eight reanalyses used in this study, where 3D-Var (4D-Var) is three-dimensional (four dimensional) variational data assimiliation and IAU is analysis update procedure.

\begin{tabular}{|c|c|c|c|c|c|}
\hline Reanalysis & Fields used & $\begin{array}{c}\text { Grid } \\
\text { spacing }\end{array}$ & $\begin{array}{l}\text { Assimilation } \\
\text { method }\end{array}$ & Sea ice cover & Microphysics scheme \\
\hline ASRv1 & $\begin{array}{l}2000-12 \\
\text { Daily precipitation, } \\
\quad \text { snowfall }\end{array}$ & $30 \mathrm{~km}$ & 3D-Var & $\begin{array}{l}\text { SSM/I and AMSR-E } \\
\text { Fractional }\end{array}$ & $\begin{array}{l}\text { Prognostic cloud condensate } \\
\text { (Tao and Simpson 1993; Tao } \\
\text { et al. 2003) }\end{array}$ \\
\hline JRA-55 & $\begin{array}{l}2000-16 \\
\text { Daily precipitation, } \\
\text { snowfall }\end{array}$ & $63 \mathrm{~km}$ & 4D-Var & $\begin{array}{l}\text { Daily (Ishii et al. 2005) } \\
\text { Threshold cover }\end{array}$ & $\begin{array}{l}\text { Prognostic cloud condensate } \\
\quad \text { (Sundqvist 1998) } \\
\text { Condensate PDF (Smith 1990) }\end{array}$ \\
\hline ERA-Interim & $\begin{array}{l}2000-16 \\
\text { Daily precipitation, } \\
\text { snowfall }\end{array}$ & $78 \mathrm{~km}$ & 4D-Var & $\begin{array}{l}\text { Weekly and daily, } \\
\text { multiple sources } \\
\text { Fractional }\end{array}$ & $\begin{array}{l}\text { Prognostic cloud condensate } \\
\text { (Tiedtke 1993) } \\
\text { Condensate PDF (Tompkins 2002) }\end{array}$ \\
\hline MERRA & $\begin{array}{l}2000-15 \\
\text { Daily precipitation, } \\
\quad \text { snowfall }\end{array}$ & $74 \mathrm{~km}$ & 3D-Var/IAU & $\begin{array}{l}\text { Weekly (Reynolds } \\
\quad \text { et al. 2002) } \\
\text { Fractional }\end{array}$ & $\begin{array}{l}\text { Prognostic cloud condensate } \\
\text { (Bacmeister et al. 2006) }\end{array}$ \\
\hline MERRA-2 & $\begin{array}{l}2000-16 \\
\text { Daily precipitation, } \\
\text { snowfall }\end{array}$ & $69 \mathrm{~km}$ & 3D-Var/IAU & $\begin{array}{l}\text { Daily (Reynolds } \\
\quad \text { et al. 2007), OSTIA } \\
\text { Fractional }\end{array}$ & $\begin{array}{l}\text { Prognostic cloud condensate } \\
\quad \text { (Bacmeister et al. 2006) } \\
\text { Condensate PDF (Molod 2012) }\end{array}$ \\
\hline NCEP R1 & $\begin{array}{l}2000-16 \\
\text { Daily precipitation }\end{array}$ & $208 \mathrm{~km}$ & 3D-Var & $\begin{array}{l}\text { Daily (Grumbine 1996) } \\
\text { Threshold cover }\end{array}$ & Layer saturation \\
\hline NCEP R2 & $\begin{array}{l}2000-16 \\
\text { Daily precipitation }\end{array}$ & $208 \mathrm{~km}$ & 3D-Var & $\begin{array}{l}\text { Daily (Grumbine 1996) } \\
\text { Threshold cover }\end{array}$ & Layer saturation \\
\hline CFSR & $\begin{array}{l}2000-10 \\
\text { Daily precipitation }\end{array}$ & $38 \mathrm{~km}$ & 3D-Var & $\begin{array}{l}\text { Daily NASA, } \\
\quad \text { (Grumbine 1996) } \\
\text { Fractional }\end{array}$ & $\begin{array}{l}\text { Prognostic cloud condensate } \\
\text { (Moorthi et al. 2001) }\end{array}$ \\
\hline
\end{tabular}

are produced through an adjustment of the forecast produced by a numerical weather prediction model to available observations (e.g., Cullather et al. 2016). The data include in situ state and dynamical variables from land stations, marine observations, aircraft, radiosonde, and profilers as well as satellite radiances. Notably, observed in situ measurements of precipitation from gauges or other means are typically not incorporated. The aim of reanalyses is to provide a more homogeneous record than is available from real-time numerical weather prediction analyses through 1) the use of an unchanging model and data assimilation system and 2) a retrospective mode that allows for incorporation of delayed observations and improved quality control (Trenberth et al. 2008; Kalnay et al. 1996; Rienecker et al. 2011). Since precipitation is not assimilated directly by reanalyses, it is particularly sensitive to the representation of physical processes within the numerical weather prediction model (Kalnay et al. 1996).

Total precipitation and snowfall (when available) from eight reanalyses are examined, including commonly used global reanalyses and one Arctic-specific reanalysis. The reanalyses include differing treatments of the Arctic sea ice pack and cloud microphysical schemes and are output at different grid resolutions and time steps. The specific reanalyses used in this study are Arctic System Reanalysis, version 1 (ASRv1; Bromwich et al. 2016); National Centers for Environmental
Prediction (NCEP)-National Center for Atmospheric Research (NCAR) reanalysis (NCEP R1; Kalnay et al. 1996); NCEP-Department of Energy (DOE) reanalysis (NCEP R2; Kanamitsu et al. 2002); NCEP Climate Forecast System Reanalysis (CFSR; Saha et al. 2010); European Centre for Medium-Range Weather Forecasts (ECMWF) interim reanalysis (ERA-Interim; Dee et al. 2011); Japanese 55-year Reanalysis (JRA-55; Kobayashi et al. 2015); NASA's Modern-Era Retrospective Analysis for Research and Application (MERRA; Rienecker et al. 2011); and MERRA, version 2 (MERRA2; Gelaro et al. 2017). The reanalyses are described in more detail in supplemental Text S1 in the online supplemental material and are summarized in Table 1. ASRv1, ERA-Interim, JRA-55, MERRA, and MERRA-2 all have total precipitation and snowfall products that are analyzed in this study; however, NCEP R1, NCEP $\mathrm{R} 2$, and CFSR only provide total precipitation. The reanalyses are not all available through 2016; thus, for comparisons between products, only data from 2000 to 2010 are used. For consistency, daily precipitation rates are computed in water equivalent millimeters per day and regridded onto the standard $25 \mathrm{~km}^{2} \mathrm{SSM} / \mathrm{I}$ polar stereographic grid (Maslanik and Stroeve 1990). A linear least squares regression is used to determine the trends in the data, and a simple Student's $t$ test is used to determine statistical significance. We exclusively focus on ocean regions (Fig. 2c) at latitudes poleward of 

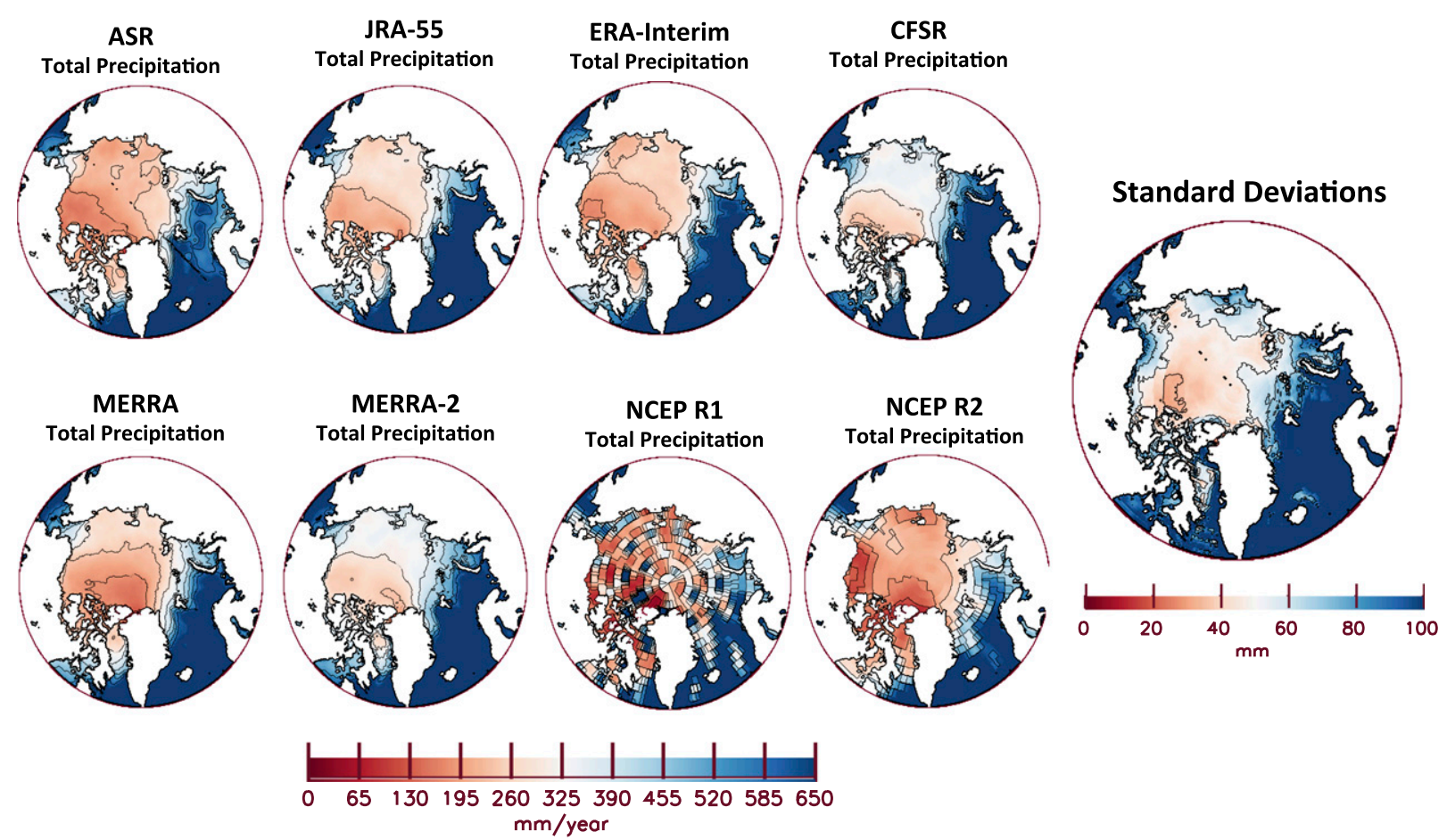

FIG. 1. Averaged 2000-10 yearly total precipitation accumulations $\left(\mathrm{mm} \mathrm{yr}^{-1}\right)$ from each of the eight reanalyses. The image on the right shows the standard deviations $(\mathrm{mm})$ between the eight reanalyses. Contour lines are on the color bars.

$60^{\circ} \mathrm{N}$-hereafter referred to as the entire Arctic Ocean domain (Fig. 2a).

\section{Results: Comparison of precipitation estimates across reanalyses}

\section{a. Magnitude of precipitation}

The mean 2000-10 cumulative annual precipitation in the Arctic varies drastically across the eight reanalyses. This is shown in Fig. 1, which highlights the regional spread in the mean estimates, along with the standard deviation of the annual mean variability between the reanalyses. NCEP R1 is known to produce a spatial "ringing" effect for variables associated with highlatitude moisture, owing to an oversimplification of the implemented diffusion equation (Kanamitsu et al. 2002); for this reason, it is not included in the interanalysis standard deviations. CFSR and MERRA-2 produce much higher amounts of precipitation compared to the other reanalyses $(\sim 43 \%-55 \%$ larger $)$, also apparent from Fig. 1.

All reanalyses, except NCEP R1, show the Beaufort Sea and north of the Canadian Archipelago receiving the least amount of precipitation $\left(\sim 150-200 \mathrm{~mm} \mathrm{yr}^{-1}\right)$. The differences between the reanalyses in the central Arctic are also small, varying $\sim 10-30 \mathrm{~mm} \mathrm{yr}^{-1}$, as shown by the standard deviation. These estimates are similar to the findings of Radionov et al. (1997) and Yang (1999), which used gauge values from the Soviet North Pole (NP) drifting ice camp stations-the only known comprehensive in situ precipitation measurements over Arctic sea ice. These stations recorded an average of $\sim 150 \mathrm{~mm} \mathrm{yr}^{-1}$ in the central Arctic during their 1937 and 1954-91 observing period. In other regions, again, the reanalyses show agreement in spatial distribution, but differ in magnitude; for example, the North Atlantic and Pacific regions receive the most annual precipitation $\left(>500 \mathrm{~mm} \mathrm{yr}^{-1}\right.$ ) because of the close proximity to storm tracks; however, the magnitudes differ widely between reanalyses, varying $\sim 120-150 \mathrm{~mm} \mathrm{yr}^{-1}$ in the east Greenland and Barents Seas.

The mean annual cumulative precipitation time series from 2000 to 2016 for the entire Arctic Ocean domain also reveals large differences of $\sim 200 \mathrm{~mm} \mathrm{yr}^{-1}$ across the reanalyses, with NCEP R2 producing the least precipitation and CFSR the most (Figs. 2a, 3; Table 2). ASRv1 shows the lowest annual totals for some years (e.g., in 2007 and 2008). The variability in total precipitation between the different reanalyses is greater than the interannual variability for the individual products (variability of less than $100 \mathrm{~mm} \mathrm{yr}^{-1}$ ). Table 2 lists the standard deviations of detrended annual cumulative precipitation for each of the products. The standard 
a)

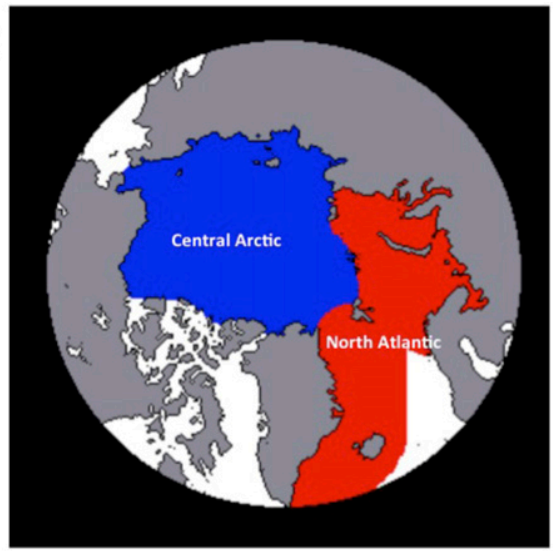

b)

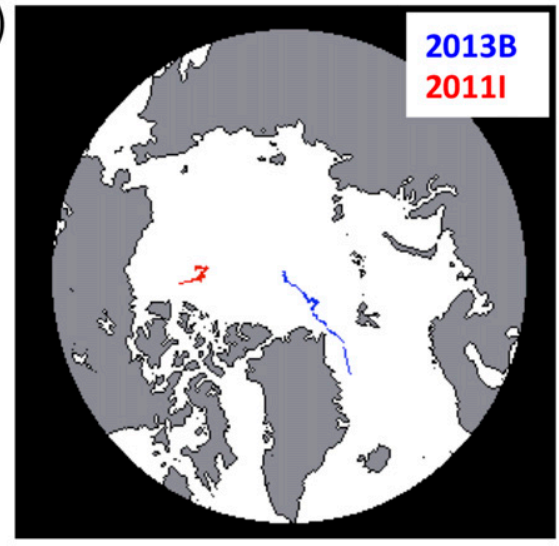

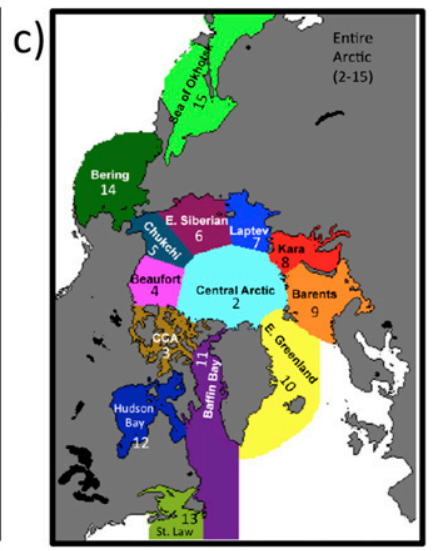

FIG. 2. (a) All oceanic regions that correspond to the regions in (c) and are north of $60^{\circ} \mathrm{N}$ latitude represent the "entire Arctic" domain. Regions in blue are classified as the "central Arctic" and regions in red are classified as the "North Atlantic" in subsequent figures. (b) IMB buoy tracks for the 2013B and 2011I buoys in Figs. 11 and 12 and S2-S6 and (c) regions of the Arctic Ocean used in Table 2.

deviations for each reanalysis product and region are similar in magnitude, however, owing to the fact that all products show similar interannual variances. This is probably because similar data are assimilated into each reanalysis each year, but the magnitude of precipitation produced is different because of the unique precipitation schemes employed by each reanalysis system. Although the same overall interannual variability is captured by all reanalyses (Fig. 3), they do not capture similar trends in the annual precipitation across 2000-16. Our results show that only ERA-Interim exhibited an increasing trend in total precipitation $\left(2.04 \mathrm{~mm} \mathrm{yr}^{-1}\right)$ that was statistically significant at the $95 \%$ confidence level, while the other reanalyses show insignificant increasing or decreasing trends. This is consistent with the findings of Lindsay et al. (2014), who found no trend across a longer 1980-2009 period in NCEP R1, NCEP R2, MERRA, and ERA-Interim precipitation data, although they did observe a slight increase in CFSR total precipitation. Because of the differing signs and low significance of the trends, it is clear that basin-scale annual precipitation has not significantly changed during this new Arctic period.

Figure 3 also shows the cumulative yearly precipitation for the North Atlantic (Greenland, Barents, and Kara Seas; red region in Fig. 2a), and the central Arctic (Chukchi, Beaufort, Laptev, and East Siberian Seas and Arctic Ocean; blue region in Fig. 2a) regions. In the North Atlantic region, the cumulative annual precipitation ranges from $\sim 600 \mathrm{~mm} \mathrm{yr}^{-1}$ for NCEP R2 and ASRv1 reanalyses to $\sim 900 \mathrm{~mm} \mathrm{yr}^{-1}$ for CFSR. In the central Arctic, the spread between the reanalyses is $\sim 150 \mathrm{~mm} \mathrm{yr}^{-1}$ —ranging from 200 to $350 \mathrm{~mm} \mathrm{yr}^{-1}$ —and is much smaller than for the entire Arctic Ocean domain. NCEP R2 is again the lowest in magnitude, but
CFSR and MERRA-2 are closer in magnitude compared to the entire Arctic (Table 2). Unlike the central Arctic, the magnitudes of CFSR and MERRA-2 in the North Atlantic differ by $100 \mathrm{~mm} \mathrm{yr}^{-1}$. Thus, the large magnitude of precipitation from CFSR for the entire Arctic is driven by the large amount of precipitation falling in the North Atlantic regions. In both the North Atlantic and central Arctic, the reanalyses show a wide range in trends. ERA-Interim, JRA-55, and MERRA show positive trends in total precipitation over the central Arctic that are statistically significant, with precipitation increasing between 1.4 and $8.2 \mathrm{~mm} \mathrm{yr}^{-1}$. Only ERA-Interim produced a statistically significant trend in total precipitation over the North Atlantic region $\left(3.8 \mathrm{~mm} \mathrm{yr}^{-1}\right)$.

This large variability between reanalyses witnessed in the North Atlantic regions (Fig. 3) may be influenced by the storm track and how each reanalysis treats these cyclone events and the amount of precipitation produced therein. But the similar interannual variability of all reanalyses can be attributed to extratropical teleconnection patterns, such as the Arctic Oscillation (AO). Rogers et al. (2001) and Simmonds et al. (2008) found that during the positive phase of the $\mathrm{AO}$, more numerous, larger, and stronger cyclones occurred. These findings suggest that during a strong negative $\mathrm{AO}$ phase, there are fewer and weaker cyclonic events and thus less precipitation, which was evident in 2010 in all reanalyses.

The reanalyses show similar average cumulative monthly Arctic precipitation cycles but again show large differences in magnitude. The annual cycle of precipitation also differs by region. Figure 4 shows the 2000-10 cumulative monthly precipitation for the entire Arctic, North Atlantic, and central Arctic regions for each 

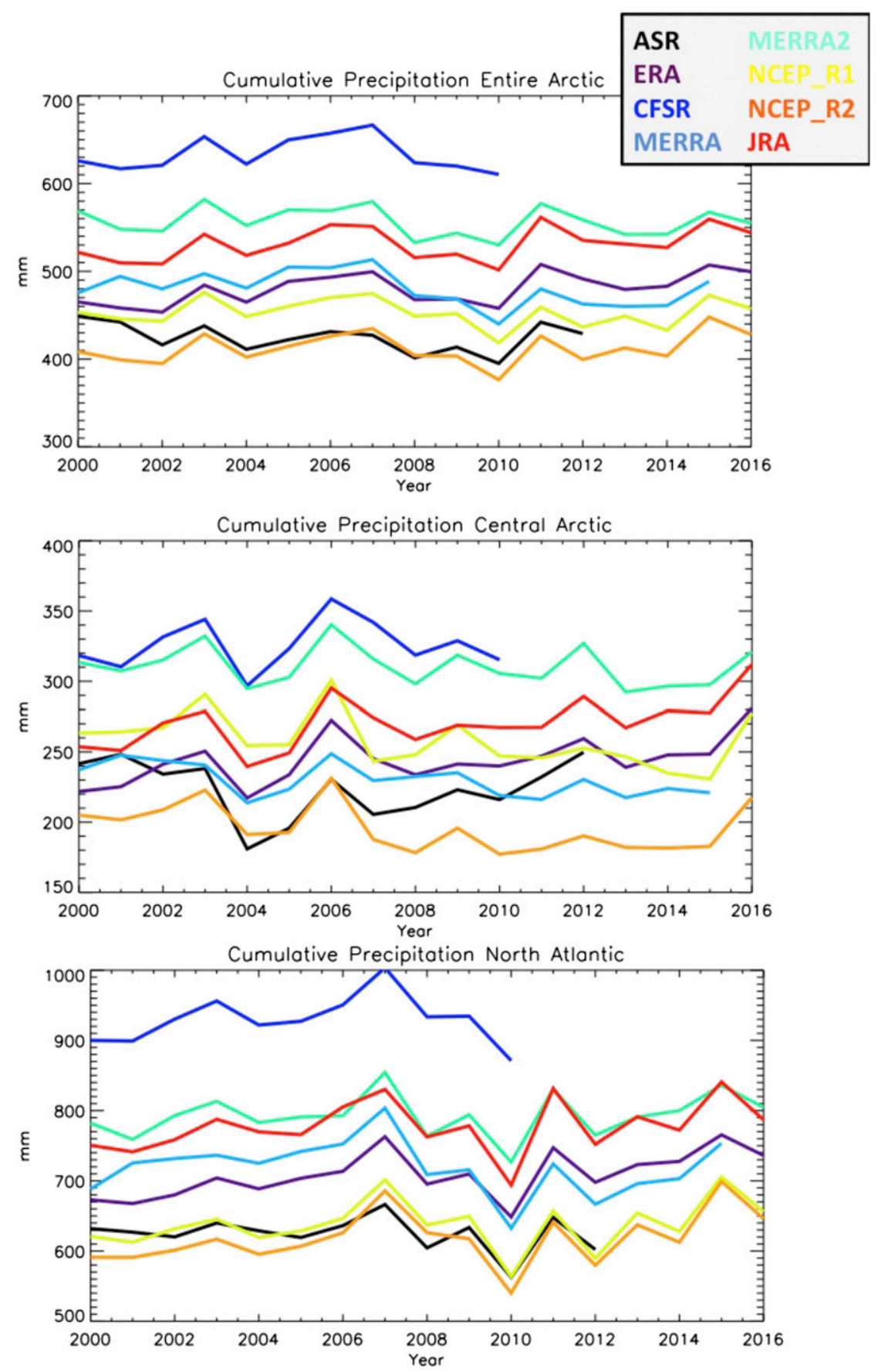

FIG. 3. Cumulative annual precipitation for the (top) entire Arctic, (middle) central Arctic, and (bottom) North Atlantic regions (see Fig. 2a) from 2000 to 2016.

reanalysis. For the entire Arctic, all reanalyses exhibit the same seasonal cycle coincident with the findings of Radionov et al. (1997) and Yang (1999), but they show larger magnitudes than those of Radionov et al. (1997) and Yang (1999), reaching a maximum in the cumulative monthly precipitation in September and October $\left(\sim 60 \mathrm{~mm}\right.$ month $\left.^{-1}\right)$, decreasing to a minimum in May $\left(\sim 30 \mathrm{~mm} \mathrm{month}^{-1}\right)$. The range in seasonal cycle between magnitudes is $\sim 25 \mathrm{~mm}$, with NCEP R2 being the smallest and CFSR the largest, similar to the annual average results. The variability across reanalyses is smallest in the months of February-April and largest 
TABLE 2. Interannual standard deviations of cumulative annual precipitation (detrended) for each reanalysis and precipitation type for each region. Values in parentheses are the mean (detrended) values.

\begin{tabular}{|c|c|c|c|c|c|c|c|c|c|}
\hline & \multicolumn{3}{|c|}{ Entire Arctic Ocean } & \multicolumn{3}{|c|}{ North Atlantic } & \multicolumn{3}{|c|}{ Central Arctic } \\
\hline & Total & Snow & Rain & Total & Snow & Rain & Total & Snow & Rain \\
\hline $\mathrm{Rv}$ & $15.2(434.1)$ & $6.5(136.2)$ & 11.8 (297.9) & $24.2(625.3)$ & 7.8 (165.7) & $21.3(469.6)$ & 20.8 & $11.6(122.1)$ & 11.1 (104.1) \\
\hline JRA-55 & $16.8(519.4)$ & $7.4(208.2)$ & $14.7(311.2)$ & 34.6 (759.1) & $15.99(256.2)$ & $29.4(502.7)$ & $14.6(254.2)$ & $11.3(185.5)$ & $9.3(68.7)$ \\
\hline ERA-Interim & $14.5(464.3)$ & $6.6(165.6)$ & 12.9 (298.6) & $26.4(668.0)$ & $14.6(222.1)$ & $23.5(455.9)$ & $13.5(229.0)$ & 7.8 (126.5) & $9.2(102.5)$ \\
\hline MERRA & $17.5(494.0)$ & $8.1(234.7)$ & $14.8(259.2)$ & 38.1 (731.1) & $17.5(297.0)$ & $28.8(434.2)$ & $9.1(240.8)$ & $10.5(204.8)$ & $6.0(36.1)$ \\
\hline MERRA-2 & $16.0(561.9)$ & $7.8(279.9)$ & $12.9(281.8)$ & $30.0(783.0)$ & $19.1(335.4)$ & 22.6 (447.6) & $13.6(315.7)$ & $12.5(262.8)$ & $6.4(52.9)$ \\
\hline NCEP R1 & $15.4(455.9)$ & - & - & $33.5(624.3)$ & - & - & 16.9 & - & - \\
\hline NCEP R2 & $17.0(405.4)$ & - & - & 35.0 (595.6) & - & - & $15.0(206.3)$ & - & - \\
\hline CFSR & $19.4(633.2)$ & - & - & $34.3(923.9)$ & - & - & $17.2(322.6)$ & - & - \\
\hline
\end{tabular}

in July-October, which likely has consequences for modeled snow depth estimates over Arctic sea ice (discussed more later).

In the North Atlantic, the precipitation minimum occurs between May and July, with $\sim 40 \mathrm{~mm} \mathrm{month}^{-1}$ in June. The maximum amount of precipitation occurs between October and January, when average magnitudes are $\sim 80 \mathrm{~mm}^{\text {month }}{ }^{-1}$. This is in stark contrast to the central Arctic, where the least amount of precipitation occurs in February and March $(\sim 10 \mathrm{~mm}$ month $^{-1}$ ), and the largest magnitude of $\sim 35 \mathrm{~mm}$ month ${ }^{-1}$ occurs in August (coincident with the largest spread between reanalyses). During the winter months, the magnitude of differences between the reanalyses in the central Arctic (excluding CFSR) is $\sim 5 \mathrm{~mm}$. The difference in the annual cycle between the central Arctic and North Atlantic is due to the active storm track during the winter months, which provides intense precipitation in the North Atlantic, but is limited to this region, since few storms enter the central Arctic during winter (Serreze et al. 1993; Zhang et al. 2004). This North Atlantic storm track is least active during the summer months, whereas more storms tend to enter the central Arctic from Siberia (Simmonds et al. 2008; Serreze and Barrett 2008), thus explaining the differences in the annual cycles between the two regions. Roughly double the amount of precipitation falls in the North Atlantic compared to the central Arctic because of the active winter storm track, and again, CFSR has the highest magnitude in all regions and months compared to the other reanalyses.

Not all of the precipitation in the Arctic Ocean domain falls as snow. In fact, several future projections of the Arctic climate show substantial increases in precipitation due to an increase in evaporation (Bintanja and Selten 2014; Kattsov et al. 2007; Rawlins et al. 2010), where more of this precipitation is falling as rain, coincident with warmer temperatures (Vihma 2014; Bintanja and Andry 2017). Significant changes in the partition of rainfall and snowfall in the new Arctic will have effects on the snowpack properties and hence the sea ice. Snowfall and rainfall are examined using five of the reanalyses (those that produce a snowfall product) in more detail in the following section.

\section{b. Magnitude of snowfall and rainfall}

On average, about $40 \%$ of the precipitation that falls in the entire Arctic Ocean domain falls as snow ( $\sim 200 \mathrm{~mm} \mathrm{yr}^{-1}$; Fig. 5, top row), compared to $\sim 500 \mathrm{~mm} \mathrm{yr}^{-1}$ of total precipitation (e.g., rain and snow; Fig. 1). There is much more variability between products for snowfall compared to total precipitation, where the standard deviations across the products and the entire Arctic are $\sim 60-70 \mathrm{~mm}$ (Fig. 5, top row standard deviation), which is about half of the total snowfall amounts for some products. There are similarities in the spatial patterns of ASRv1 and ERA-Interim, but the magnitude of ERA-Interim's snowfall is larger by $\sim 30 \mathrm{~mm} \mathrm{yr}^{-1}$. This difference is driven by a $\sim 57 \mathrm{~mm} \mathrm{yr}^{-1}$ difference in the snowfall in the North Atlantic, whereas the magnitudes are similar in the central Arctic. MERRA-2 produced significantly more snowfall than the other reanalyses, mostly driven by $\sim 100 \mathrm{~mm} \mathrm{yr}^{-1}$ larger cumulative snowfall in the central Arctic. Overall, the spatial patterns suggest that the largest magnitudes of snowfall occur in the North Atlantic regions, with some significant regions of snowfall extending into the central Arctic along the storm track.

The amount of rainfall occurring in the central Arctic is $\sim 45 \%$ of the annual precipitation for ASRv1 and ERA-Interim, $\sim 25 \%$ for JRA-55, and $\sim 15 \%$ for MERRA and MERRA-2. While these amounts of rainfall are high, the majority of the precipitation occurs during the warm months, and warming temperatures could be causing reanalyses to produce more rainfall; however, spatially, the amount and locations of rainfall vary across all reanalyses (Fig. 5, bottom). Standard deviations between reanalyses are on average $30-40 \mathrm{~mm}$ 

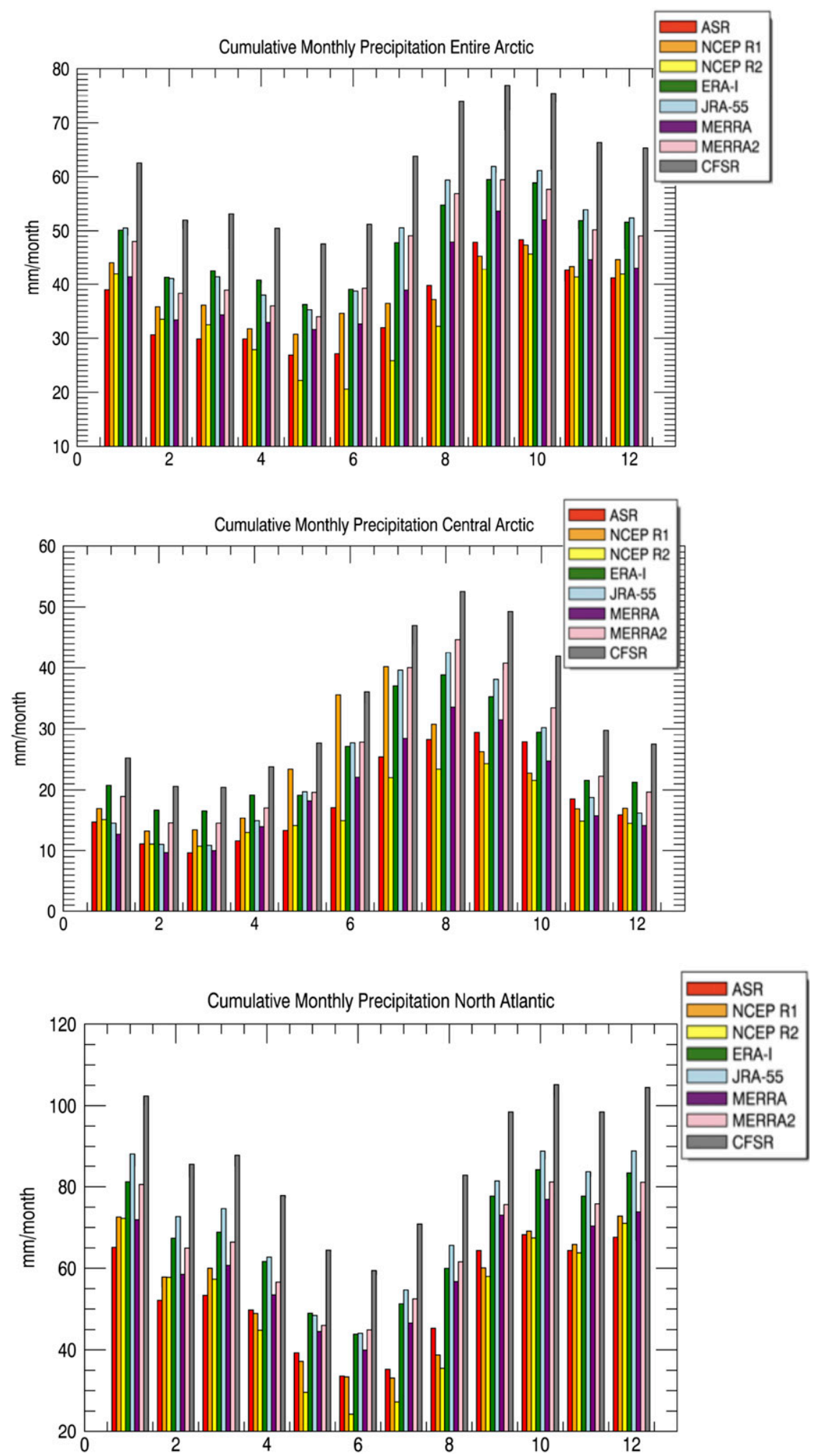

FIG. 4. The mean 2000-10 cumulative monthly precipitation for the (top) entire Arctic, (middle) central Arctic, and (bottom) North Atlantic. Regions correspond to those in Fig. 2a. 

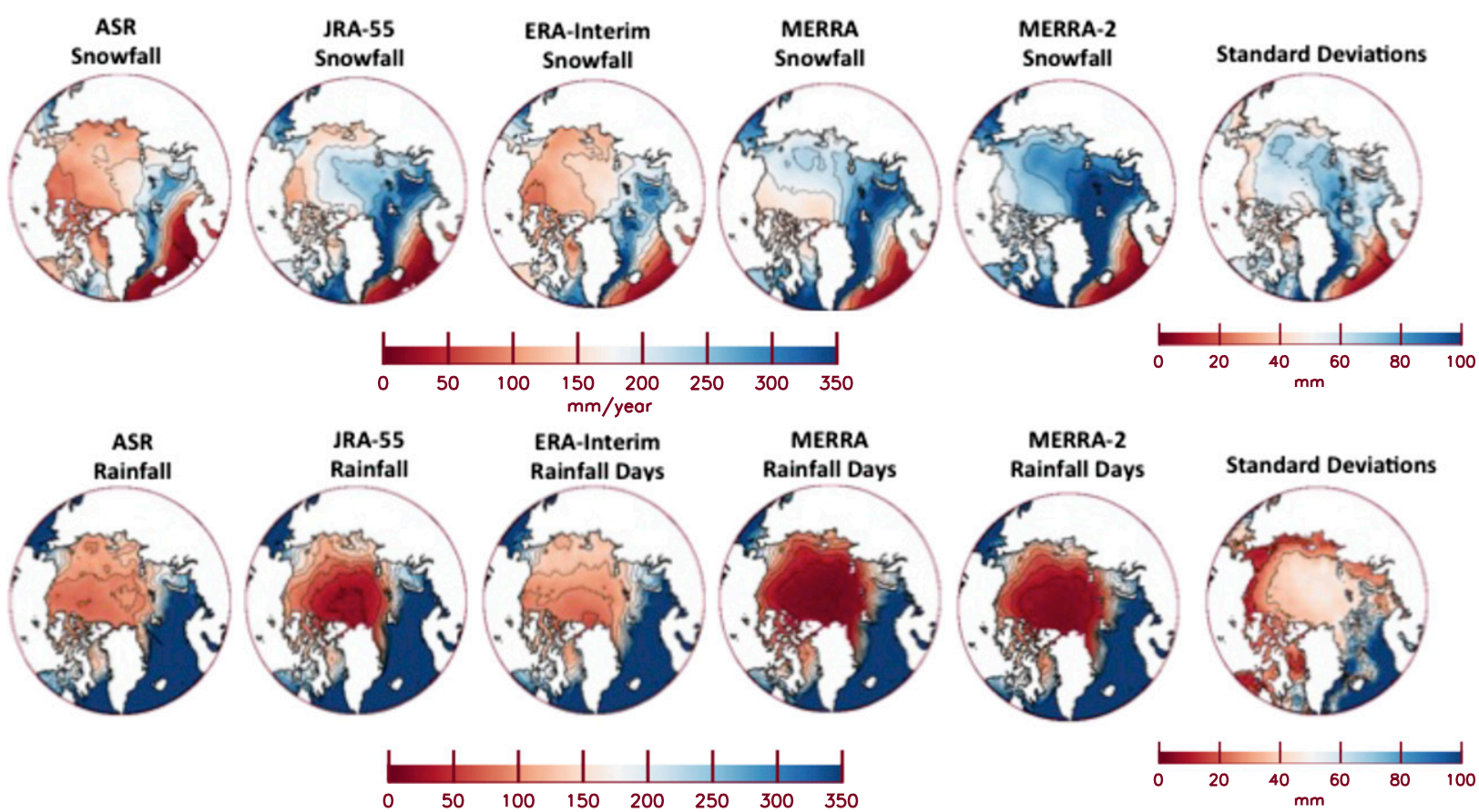

FIG. 5. Average 2000-10 yearly cumulative (top) snowfall and (bottom) rainfall. (right) The standard deviations across the different products. Contour lines are on the color bars.

and are highest along the east coast of Greenland, extending into the central Arctic. The average 2000-10 cumulative yearly rainfall in the new Arctic shows that the central Arctic receives around $73 \mathrm{~mm} \mathrm{yr}^{-1}$ of rain, with much larger amounts in the North Atlantic regions $\left(\sim 462 \mathrm{~mm} \mathrm{yr}^{-1}\right)$. JRA-55 has the highest rainfall amounts in the North Atlantic and entire Arctic Ocean, but has lower amounts for the central Arctic, where ERA-Interim and ASRv1 have the highest rainfall amounts. MERRA and MERRA-2 have the lowest rainfall amounts compared to the other reanalyses, but with the cumulative snowfall, they had shown the largest amounts.

In general, the reanalyses show a decrease in the amount of snowfall between 2000 and 2016 and are associated with an increase in rainfall in the new Arctic. All reanalyses show a decreasing trend in snowfall over the entire Arctic, but only MERRA and MERRA-2 $\left(-2 \mathrm{~mm} \mathrm{yr}^{-1}\right)$ are statistically significant at $95 \%$ (Fig. 6). While there is interannual variability, trends in snowfall over the central Arctic differ, thus there does not appear to be any definitive changes in snowfall in that region. In the North Atlantic region, however, it is clear that there is a decrease in snowfall, with ASRv1 $\left(-1.53 \mathrm{~mm} \mathrm{yr}^{-1}\right)$, JRA-55 (-7.52 $\left.\mathrm{mm} \mathrm{yr}^{-1}\right)$, MERRA $\left(-2.21 \mathrm{~mm} \mathrm{yr}^{-1}\right)$, and MERRA-2 $\left(-2.79 \mathrm{~mm} \mathrm{yr}^{-1}\right)$ producing statistically significant trends. The amount of rainfall in the entire Arctic Ocean is increasing, with ERA-Interim and JRA-55 having statistically significant trends of 2.09 and $9.27 \mathrm{~mm} \mathrm{yr}^{-1}$, respectively. Similar statistically significant trends for ERA-Interim $\left(1.09 \mathrm{~mm} \mathrm{yr}^{-1}\right)$ and JRA-55 (6.36 $\left.\mathrm{mm} \mathrm{yr}^{-1}\right)$ are present in the central Arctic. However, the increase in the entire Arctic was driven by the North Atlantic regions, where large amounts of rainfall $\left(\sim 450 \mathrm{~mm} \mathrm{yr}^{-1}\right)$ occur. Statistically significant, positive trends are present in MERRA-2 (4.04 $\left.\mathrm{mm} \mathrm{yr}^{-1}\right)$, ERA-Interim $\left(4.01 \mathrm{~mm} \mathrm{yr}^{-1}\right)$, and JRA$55\left(17.5 \mathrm{~mm} \mathrm{yr}^{-1}\right)$. In fact, JRA-55 has shown a 276-mm increase in rainfall between 2000 and 2016 in the North Atlantic.

\section{c. Frequency of precipitation}

The analysis thus far has found that precipitation from the reanalyses differs considerably in monthly and annual means, and in the magnitude and strength of trends, but shows reasonable similarity in the interannual variability; but what about the frequency of Arctic precipitation? Figure 7 shows the average number of days each year in 2000-10 that precipitation occurred (greater than $0 \mathrm{~mm} \mathrm{day}^{-1}$ ), which suggests that, on average, the entire Arctic has some precipitation occurring virtually every day of the year. JRA-55 precipitates $\sim 320$ days on average in the central Arctic, with ERAInterim and CFSR precipitating $\sim 280$ days. ERAInterim and CFSR have similar spatial patterns for the 

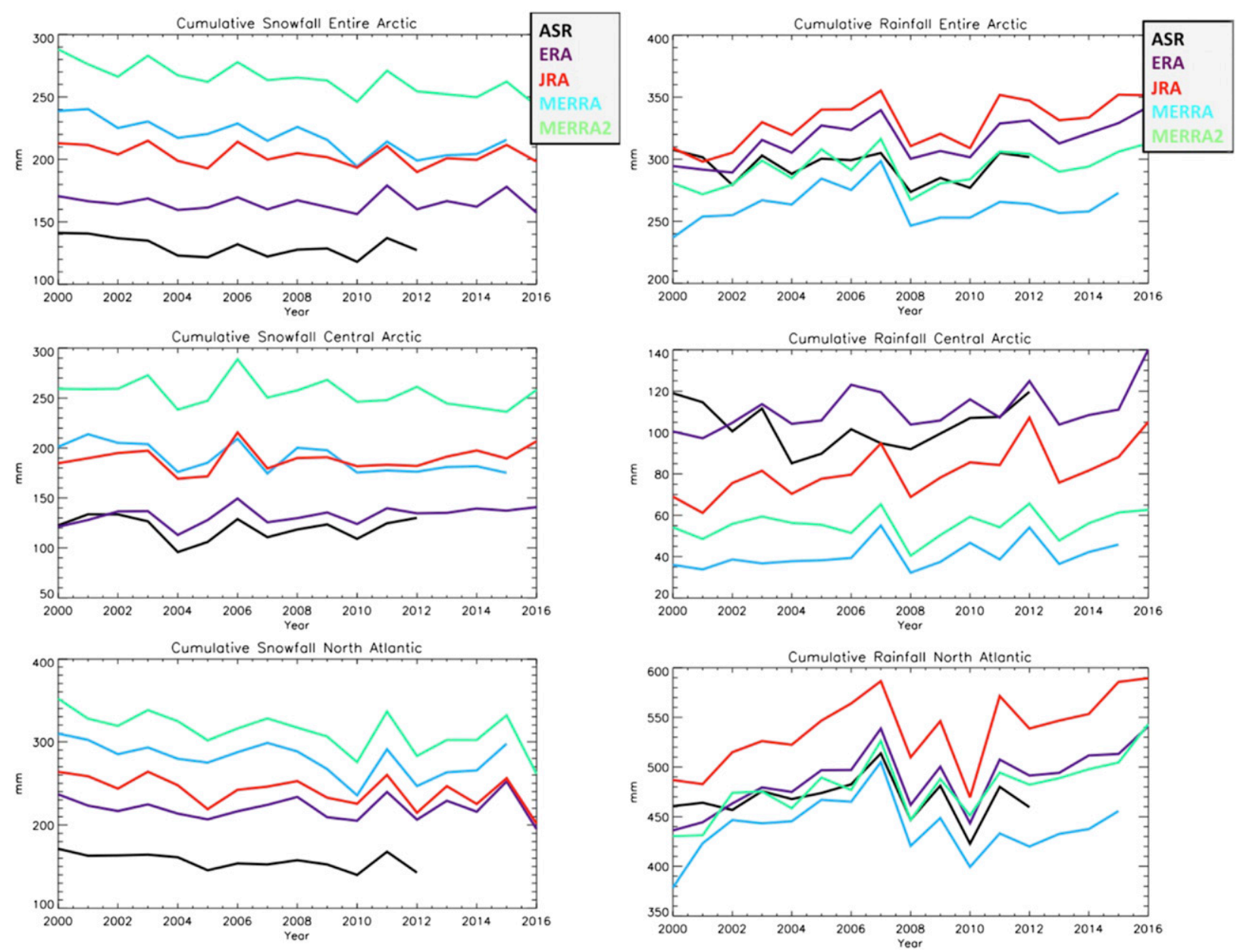

FIG. 6. Annual cumulative (left) snowfall and (right) rainfall from 2000 to 2016 for the (top) entire Arctic, (middle) central Arctic, and (bottom) North Atlantic regions.

frequency across the Arctic, with the lowest frequency ( $\sim 230$ days) occurring in the Beaufort Sea and just north of Greenland, and the largest frequency in the North Atlantic. This is notable because CFSR has $\sim 200 \mathrm{~mm} \mathrm{yr}^{-1}$ more precipitation in the Arctic than ERA-Interim (Fig. 1) but a similar number of precipitation days. Thus, the magnitude of individual precipitation events in CFSR is much larger than ERA-Interim. Even though ERAInterim has the smallest precipitation frequency for the central Arctic, it is still inconsistent with the twentieth century ice drift camp record of Radionov et al. (1997), which found precipitation occurring on only $\sim 150$ days $\mathrm{yr}^{-1}$.

\section{d. Frequency of snowfall and rainfall}

Snowfall is the most frequent type of precipitation occurring in the Arctic. As shown in Fig. 8, ASRv1, MERRA, and MERRA-2 suggest similar spatial patterns of snowfall frequency, with an average of $\sim 270$ days $\mathrm{yr}^{-1}$ for the entire Arctic Ocean. JRA-55 produces snowfall around $\sim 220$ days $\mathrm{yr}^{-1}$, while ERA-Interim has the least frequent snowfall $\left(\sim 170\right.$ days $\left.\mathrm{yr}^{-1}\right)$, with much less frequent snowfall in the Beaufort and Chukchi Seas (Fig. 8, top). Among the reanalyses in the central Arctic, the frequency in snowfall varies by $60-80$ days. Differences are especially large in the western Arctic, while there is generally better agreement on the frequency of snowfall in the North Atlantic. For the North Atlantic (not shown), the snowfall frequencies for the ERA-Interim and JRA-55 are comparable; both are roughly 50 days fewer than for ASRv1, MERRA, and MERRA-2.

In the reanalyses examined here, rainfall occurs $\sim 50 \%$ less frequently than snowfall over the entire Arctic Ocean domain (depending on the reanalysis; Fig. 8, bottom row). ERA-Interim and JRA-55 have the highest daily rainfall frequency, with MERRA and MERRA-2 slightly less and ASRv1 with the least. 
ASR

Total Precipitation Days

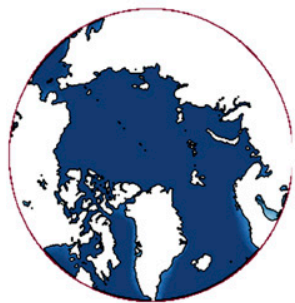

MERRA

Total Precipitation Days

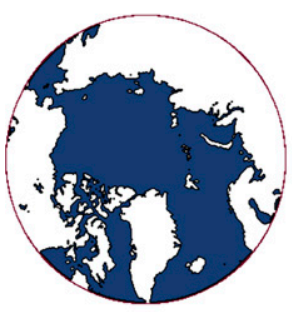

JRA-55

Total Precipitation Days

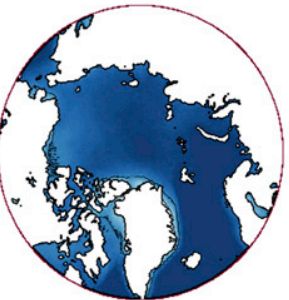

MERRA-2

Total Precipitation Days
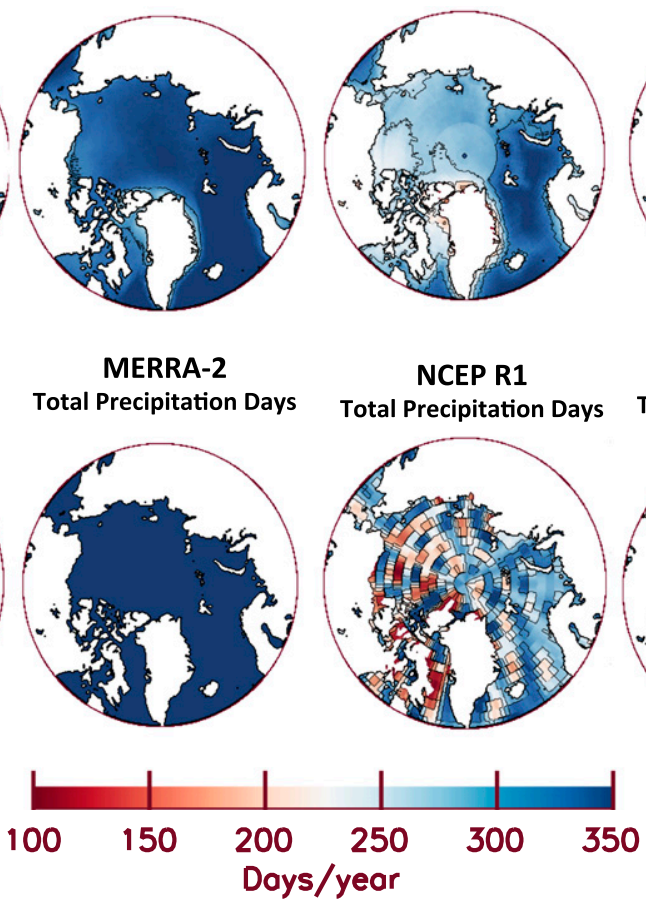

NCEP R1

Total Precipitation Days

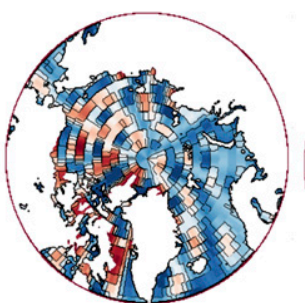

CFSR

Total Precipitation Days Total Precipitation Days

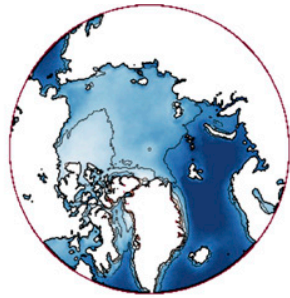

NCEP R2

Total Precipitation Days

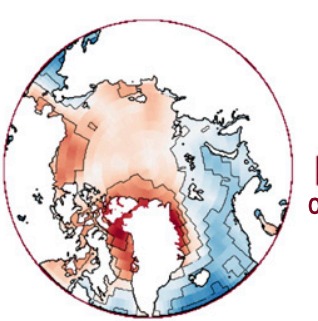

Standard Deviations
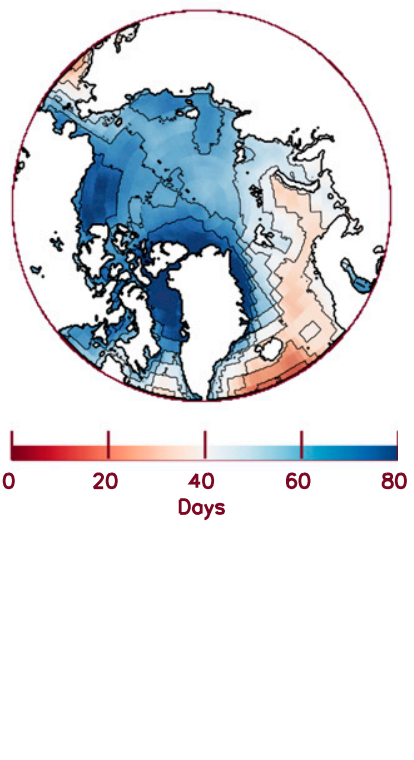

FIG. 7. Mean 2000-10 number of days within a year during which some "total precipitation" (e.g., both rainfall and snowfall) occurs. (right) The standard deviations between the eight reanalyses. Contour lines are shown on the color bar.

ERA-Interim thus differs from other reanalyses in having the most frequent rainfall and the least frequent snowfall in the central Arctic. Spatially, the reanalyses' rainfall frequency agrees most closely near the North Pole $\left(\sim 20\right.$ days $\left.\mathrm{yr}^{-1}\right)$, with largest differences in all of the peripheral seas $(\sim 30$ days). This suggests a greater uncertainty in lower latitudes where phase transitions are more likely.

While there are discrepancies in the frequency of rainfall among different reanalyses, it is apparent that rainfall is becoming more frequent in the new Arctic (Fig. 9), which could be a result of warming temperatures and increasing humidity and water vapor during this time period (e.g., Boisvert and Stroeve 2015). This is particularly notable as the overall frequency of total precipitation does not change in the reanalyses (not shown). The fraction of the total number of precipitation events falling as rain each year for all reanalyses and regions is increasing, with nearly all having statistically significant trends (except for ERA-Interim for the entire and central Arctic). This provides a clear indication that the frequency of rainfall increased in the new Arctic from $2.7 \%$ to $5.4 \%$ over the period $2000-16$. Rainfall events became more frequent (all reanalyses statistically significant; Fig. 9) in the North Atlantic region, and although changes in the magnitude and frequency of cyclones in the North Atlantic remain uncertain (Zhang et al. 2004; Simmonds et al. 2008), a warming climate could suggest warm-air advection associated with more of these rain-producing storms.

It is also well known that reanalyses have a problem with producing too-frequent precipitation events (e.g., Dai 2006) because of the oversensitivity of their atmospheric and microphysical schemes on a global scale; the results shown here suggest similar issues are locally applicable to the Arctic. In the Arctic, the presence or absence of small but immeasurable daily precipitation events, or trace precipitation (TP), is largely unknown. We thus explore this in more detail in the following section.

\section{e. $T P$}

Uncertainty surrounding the concept of TP over the Arctic warrants a more detailed analysis. Radionov et al. (1997) classified TP as a daily precipitation rate of less than $1 \mathrm{~mm} \mathrm{day}^{-1}$, which we adopt in this study. Figure 10a shows the average number of days in 2000-16 where TP occurs for the eight reanalyses, thus demonstrating large differences in the presence of TP. ASRv1 and MERRA see $\sim 300$ days $\mathrm{yr}^{-1}$ of TP in the central 

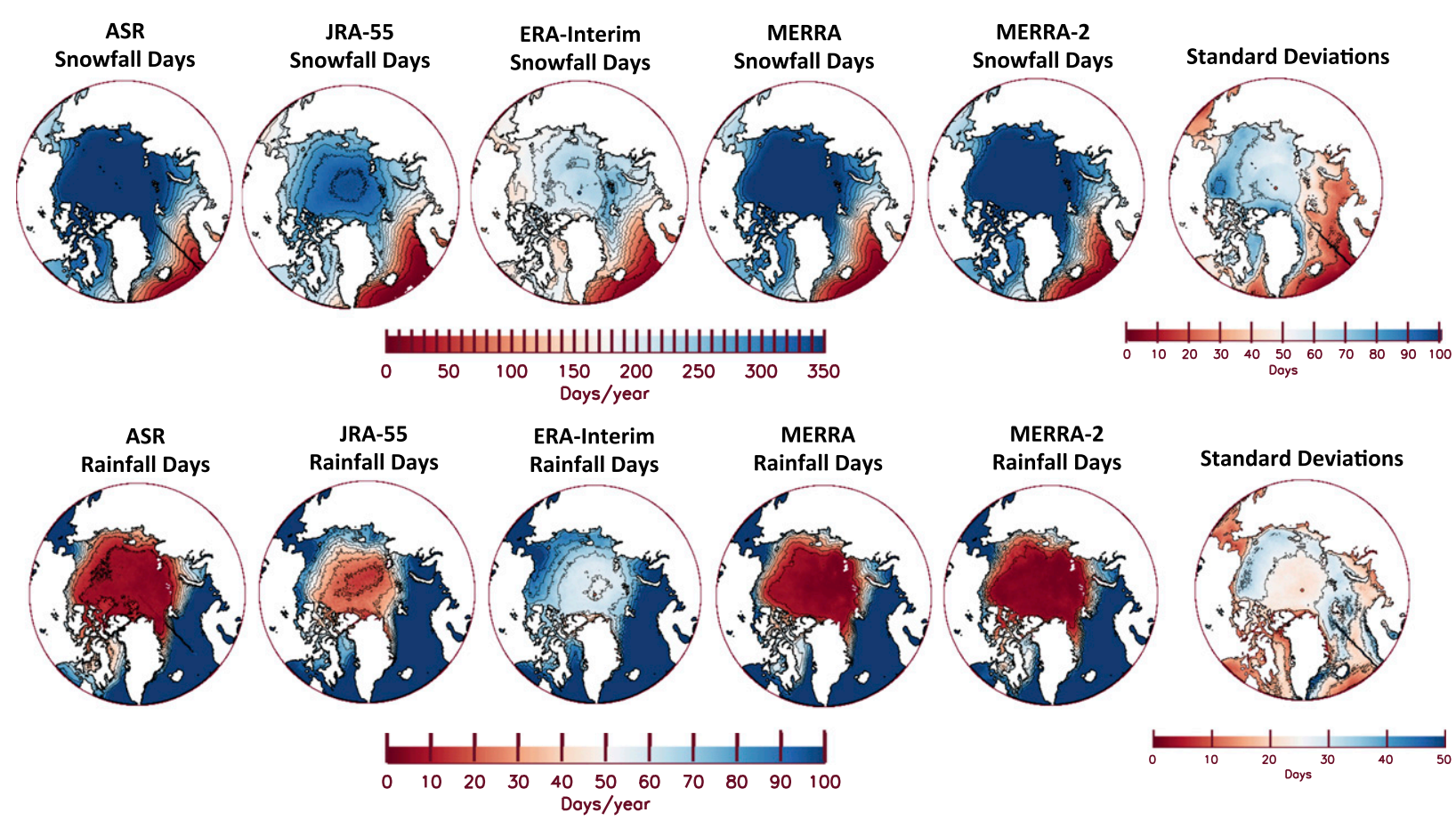

FIG. 8. Average 2000-10 annual number of days of (top) snowfall and (bottom) rainfall (days $\mathrm{yr}^{-1}$ ), with contours every 10 days. (right) The standard deviation across the products. Contour lines are on the color bars.

Arctic, with the regions of greater than 330 days $\mathrm{yr}^{-1}$ occurring either in the Beaufort and/or Lincoln Seas. MERRA-2 has slightly less TP, especially in the eastern central Arctic. JRA-55 and ERA-Interim have smaller TP frequency compared to the others, with JRA-55 having slightly more TP compared to ERA-Interim (250 vs 200 days $\mathrm{yr}^{-1}$ ). TP days from ERA-Interim are comparable to bias-corrected gauge measurements from Yang (1999). CFSR and NCEP R2 have the least frequent trace precipitation $\sim 150$ days $\mathrm{yr}^{-1}$, which for CFSR could be due in part to its large precipitation magnitudes.

The annual cumulative TP between 2000 and 2010 in Fig. 10b also shows large differences among the reanalyses. EP R2, ASRv1, and JRA-55 produce the least amount of cumulative TP $\left(\sim 40 \mathrm{~mm} \mathrm{yr}^{-1}\right)$. MERRA and MERRA-2 have a high frequency but a much larger cumulative TP $\left(\sim 90-100 \mathrm{~mm} \mathrm{yr}^{-1}\right)$. CFSR, on the other hand, produces the least frequent TP but has the third highest cumulative TP overall. The standard deviations across the products are largest in the central Arctic, especially in the Fram Strait. The reasons for the differences between the frequency and magnitudes of the TP are likely due in part to how the individual reanalyses produce precipitation, and this appears to be exacerbated over the sea ice pack, where the standard deviations are largest.
To highlight the impact of TP on the reanalyses' biases, we repeated our comparison after removing the daily TP from each average cumulative yearly precipitation from 2000 to 2010 (e.g., Fig. 1). This remaining cumulative precipitation is shown in Fig. S1. After the TP is removed, all (except NCEP R1) have similar regional variability, characteristics, and magnitudes. The least amount of precipitation occurs over the Beaufort Sea and north of Greenland, and increases slightly toward the Russian side of the Arctic. Higher amounts of precipitation occur in the regions of the storm track in the North Atlantic. The range in magnitudes of this precipitation has also decreased, especially in the central Arctic. In all regions of the central Arctic, the standard deviation has decreased by about $10 \mathrm{~mm}$, thus reducing the uncertainty between products (Table 3 ). Further work needs to be undertaken to better assess this potentially erroneous TP; however, this is beyond the scope of this study.

\section{f. Comparisons with buoy data}

A total of 57 IMB buoys (Perovich et al. 2017) were used to assess the quality of the reanalyses' precipitation products. These buoys measure the surface position with an accuracy of $\sim 1 \mathrm{~cm}$ every $4 \mathrm{~h}$ using a sonic rangefinder (Perovich et al. 2017). This information, together with the initial snow depth conditions, is used to calculate the 

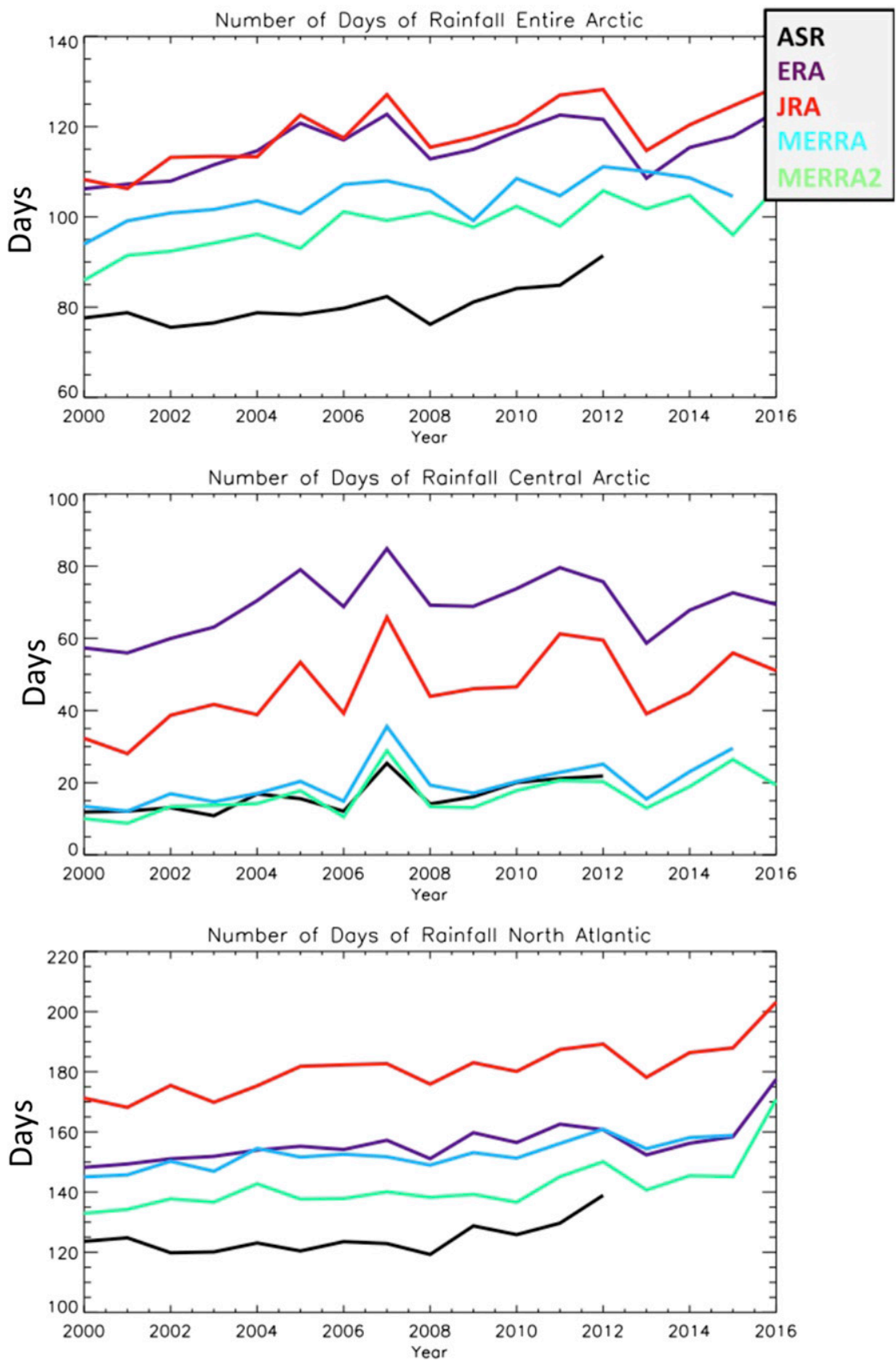

FIG. 9. Annual number of days of rainfall from 2000 to 2016 for the (top) entire Arctic, (middle) central Arctic, and (bottom) North Atlantic.

changes in snow depth as the buoys drift with the sea ice pack. The detected changes in snow depth are due to snowfall, drifting/blowing snow, rainfall, or melt events. For this study, we have chosen any occasion when the snow depth increased by $1 \mathrm{~cm}$ or more in a day as a snowfall event based on the instrumental accuracy.

The reanalyses are first compared with the IMB buoys to determine if they have any skill in simulating snowfall events. For each day that the buoy records a $1 \mathrm{~cm}$ or greater increase in depth, each reanalysis is checked for a $1 \mathrm{~mm} \mathrm{day}^{-1}$ or greater precipitation event. If both produce an event, then this is considered true positive. If a reanalysis shows an event but the buoy does not show an increase in depth, then this is classified as a false positive. Last, if no precipitation is produced and the buoy records a snow event, then this case is considered a 
a)

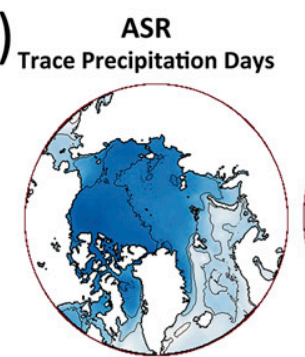

MERRA

Trace Precipitation Days

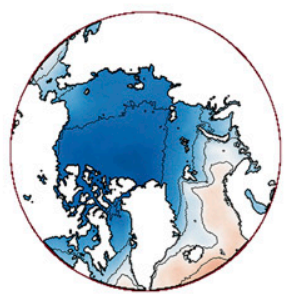

JRA-55

Trace Precipitation Days

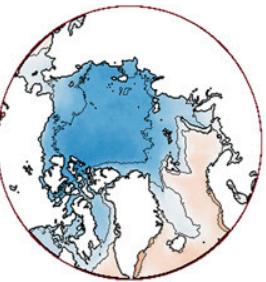

MERRA-2

Trace Precipitation Days
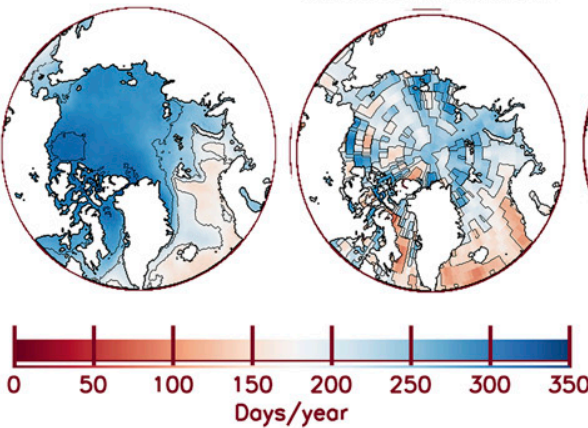

ERA-Interim

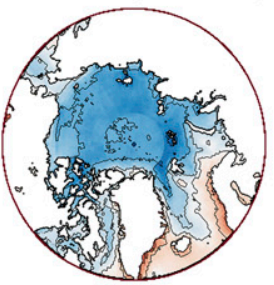

NCEP R1

Trace Precipitation Days

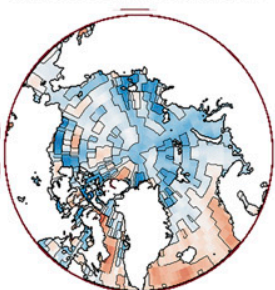

CFSR

Trace Precipitation Days Trace Precipitation Days

NCEP R2

Trace Precipitation Days
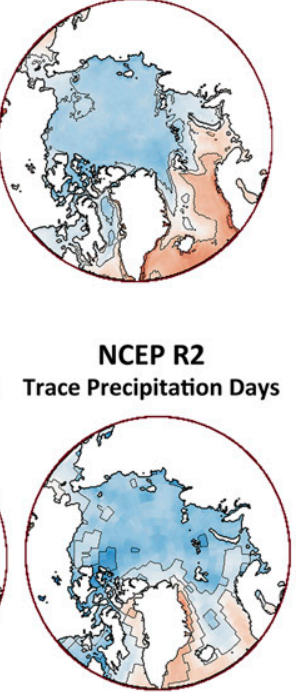

\section{Standard Deviations}
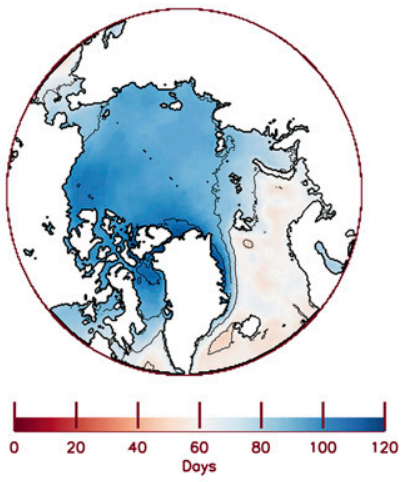

b)
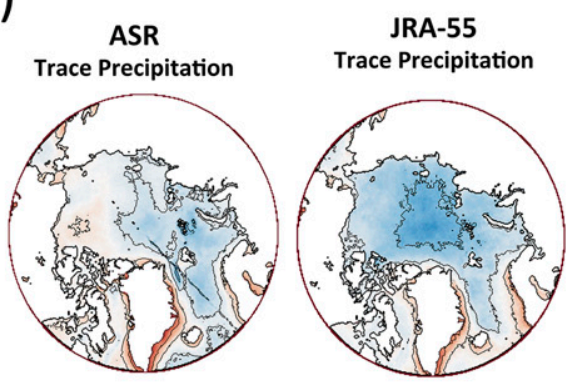

ERA-Interim

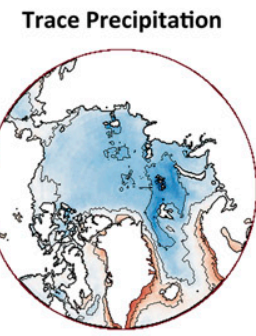

Trace Precipitation
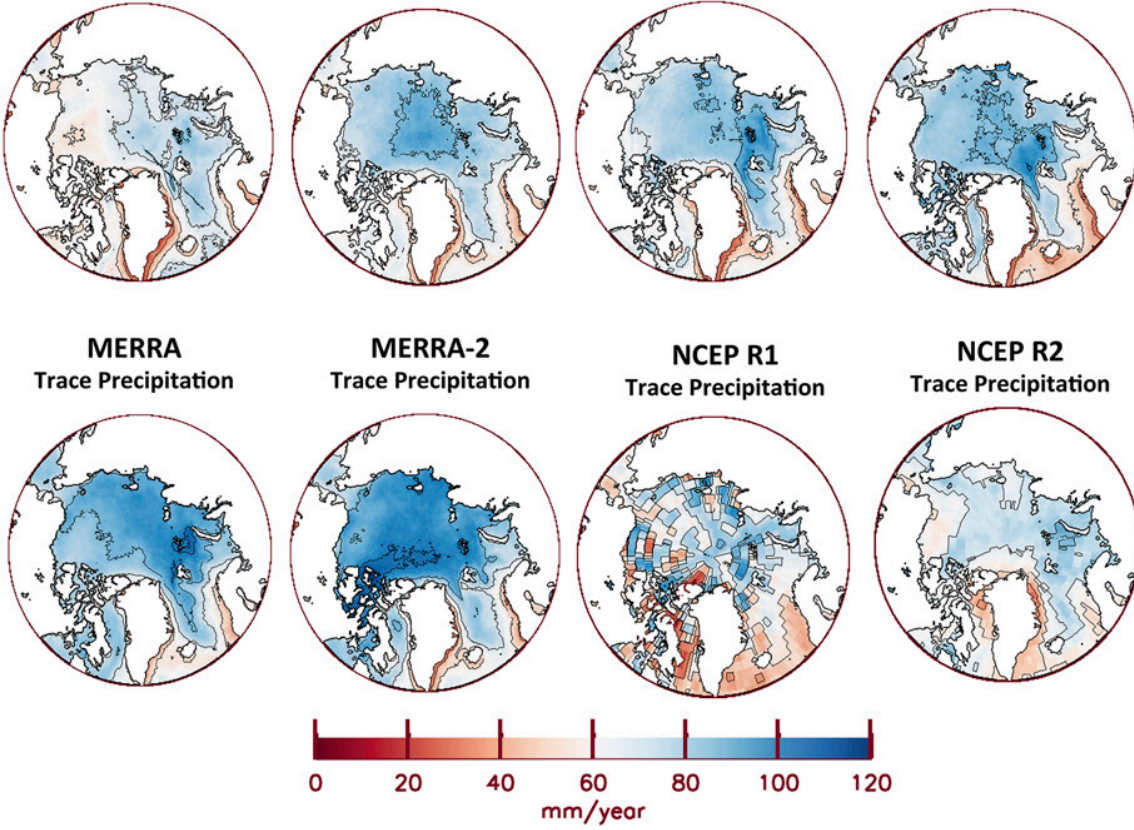

NCEP R2

Trace Precipitation
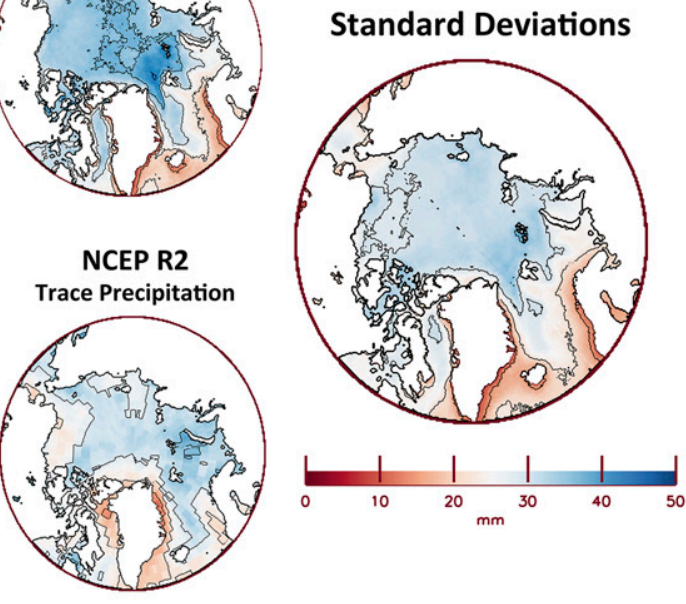

FIG. 10. (a) Average annual 2000-10 number of days of TP, classified as precipitation rates less than $1 \mathrm{~mm} \mathrm{day}^{-1}$. (b) Average annual 2000-10 cumulative TP, where TP is classified as any daily precipitation rate less than $1 \mathrm{~mm} \mathrm{day}{ }^{-1}$. The larger image shows the standard deviations [days in (a) and $\mathrm{mm}$ in (b)] between the eight reanalyses. This figure shows the TP taken from the total precipitation products. Contours are on the color bars. 
TABLE 3. Average standard deviations $(\mathrm{mm})$ in total precipitation for 2000-10 with TP $\left(<1 \mathrm{~mm} \mathrm{day}^{-1}\right)$ and without TP.

\begin{tabular}{lrc}
\hline \multicolumn{1}{c}{ Regions } & With TP & Without TP \\
\hline Entire Arctic & 93.59 & 87.45 \\
Baffin Bay & 93.90 & 87.35 \\
East Greenland Sea & 152.46 & 151.00 \\
Barents Sea & 126.88 & 125.57 \\
Kara Sea & 72.06 & 66.30 \\
Laptev Sea & 57.62 & 46.02 \\
East Siberian Sea & 50.80 & 40.47 \\
Chukchi Sea & 59.24 & 49.31 \\
Beaufort Sea & 47.25 & 34.51 \\
Canadian Archipelago & 60.44 & 46.76 \\
Central Arctic & 47.95 & 39.79 \\
\hline
\end{tabular}

false negative. The results for each reanalysis are shown in Table 4. These results show that overall the reanalyses match up with the buoy events over $70 \%$ of the time (excluding CFSR), with MERRA having the highest percentage $(83 \%)$, followed by NCEP R2 $(82 \%)$ and ERA-Interim (80\%). These results show that the reanalyses, even when TP is removed, produce many more events compared to what the buoys are recording $\sim 11 \%$ $27 \%$ of the time. These differences could arise because of the wrong precipitation phase, buoy instrument error, or blowing snow events, which would prevent snow accumulation under the buoy sonic rangefinder. The small percentages for the false negatives demonstrate that the reanalyses rarely ever miss a precipitation event that the buoy detects $(5 \%-7 \%$ of the time) and instead tend to simulate too many precipitation events.

While it is promising that these reanalyses pick up the majority of these snowfall events simultaneously with the buoys, the magnitudes of these events remain uncertain. This is similar to the findings of Cullather and Bosilovich (2011), who compared MERRA precipitation data and North Pole drifting ice station data and found discrepancies in the magnitude of events but reasonable correlations. Our results show that the range of precipitation rates can be anywhere between 1 and $20 \mathrm{~mm} \mathrm{day}^{-1}$ across the products, showcasing how differing cloud microphysical schemes may produce drastically different intensity of precipitation during these events.

Figure 11 shows the total precipitation rates and the buoy snow depth for the 2013B (Fig. 11a) and 2011I buoys (Fig. 11b), respectively. Figures S3 and S4 and Texts S3 and S4 show/discuss the snowfall (Figs. S3a, S4a) and rainfall rates (Figs. S3b, S4b) for these buoys. These buoys were chosen because they highlight the different precipitation regimes of the North Atlantic in the Fram Strait (2013B) and the central Arctic in the Beaufort Sea (2011I; buoy tracks shown in Fig. 2b). As in our earlier analyses, we remove the TP from these figures to highlight precipitation "events" more clearly (see Fig. S2 for an example with TP included).

The 2013B buoy (Fig. 11a), deployed on 10 April (day 100), witnessed a period of snow accumulation during the first 3 months. In early July (day 185) the snow depth dropped rapidly, either because of rainfall, melt, or both. Beginning in early September ( day 244), snow accumulated over a series of five large snowfall events, likely associated with cyclone activity in the Fram Strait as the buoy air pressure readings dropped below $1000 \mathrm{hPa}$ during those time periods. The majority of the reanalyses' precipitation events were coincident with the buoy snow accumulation events (Fig. 11a), while some events appear to be clustered around periods of decreasing buoy snow depth and are thus assumed to be rainfall events (Fig. S3b), especially during the summer months. Others still are due to buoy instrument error, which is described in more detail in the Text S2. Precipitation rates from the reanalyses range from $>1$ to $23 \mathrm{~mm} \mathrm{day}^{-1}$, highlighting the difficulty in producing a common or realistic precipitation rate.

The IMB buoy 2011I, deployed on 5 August (day 217), had substantially fewer snow accumulation events as

TABLE 4. IMB buoys and reanalyses contingency table using a $>1 \mathrm{~mm} \mathrm{day}^{-1}$ precipitation threshold and a $>1 \mathrm{~cm} \mathrm{day}^{-1}$ change in snow depth from the IMB buoys. True indicates reanalysis and buoy concurrently predict a daily snow event. False positives denote times when the buoy predicts an event and the reanalysis does not, while false negatives indicate occurrences of the reverse.

\begin{tabular}{lcccr}
\hline \hline & True $(\%)$ & False positives $(\%)$ & False negatives (\%) & No. values compared \\
\hline ASRv1 & 76 & 17 & 7 & 8554 \\
CFSR & 67 & 27 & 6 & 6106 \\
ERA-Interim & 80 & 15 & 5 & 16779 \\
JRA-55 & 77 & 18 & 5 & 16777 \\
MERRA & 83 & 11 & 6 & 16160 \\
MERRA-2 & 78 & 17 & 5 & 16779 \\
NCEP R1 & 78 & 15 & 7 & 16779 \\
NCEP R2 & 82 & 12 & 6 & 16779 \\
\hline
\end{tabular}




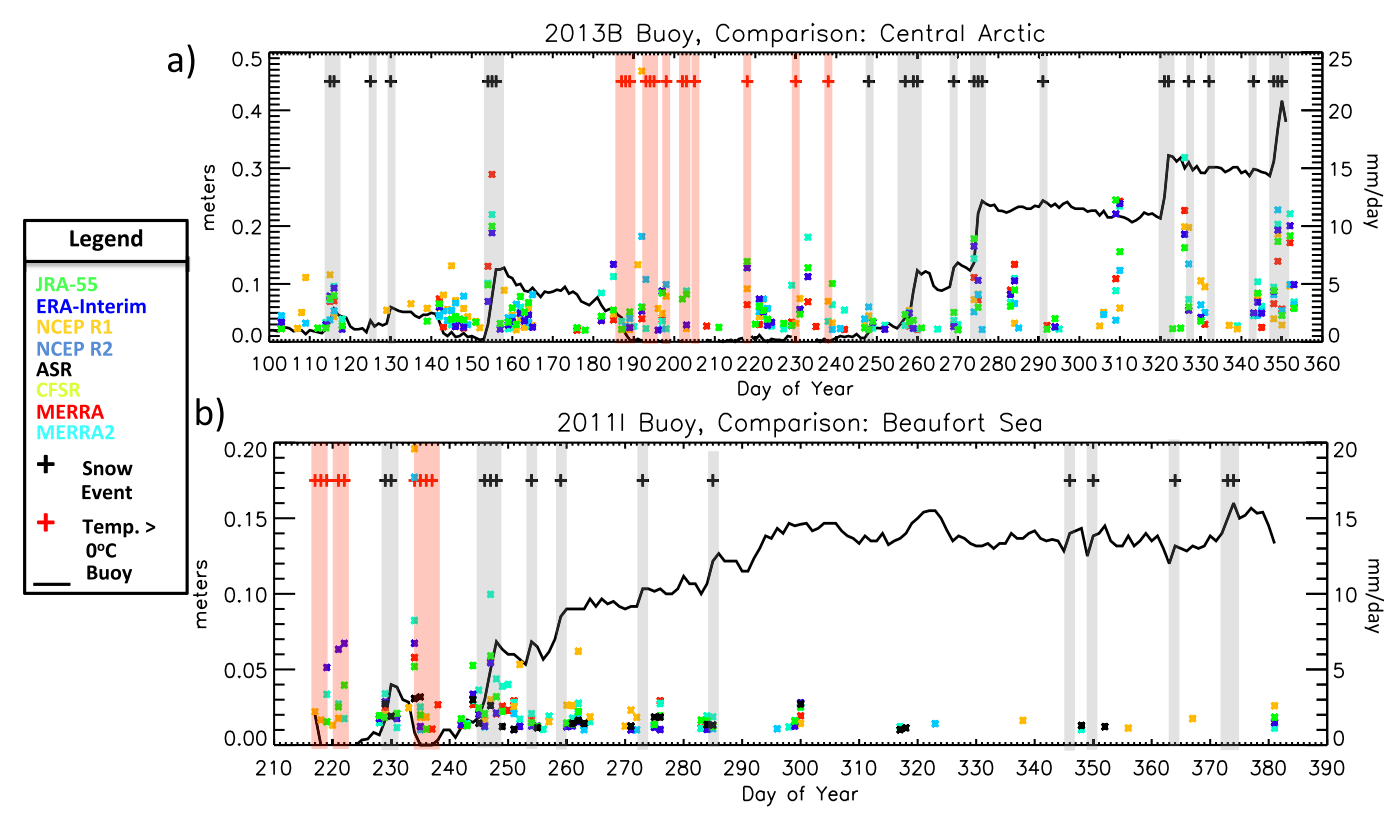

FIG. 11. The (a) 2013B and (b) 2011I buoy (tracks shown in Fig. 2b) snow depth (m; black line) beginning on 10 Apr 2013 (for 2013B) and 17 Aug 2011 (for 2011I). Each color square represents the daily precipitation rate ( $\mathrm{mm} \mathrm{day}{ }^{-1}$; right axis) at the location of the buoy from each reanalysis. The snowfall events captured by the buoys are marked with the black + marks and gray shaded boxes, and the air temperatures that are greater than $0^{\circ} \mathrm{C}$ are marked with the red + marks and red shaded boxes. The total precipitation rates are shown for all reanalyses except for CFSR and ASRv1 in 2013B and CFSR in 2011I.

compared to 2013B, most likely because of its location in the Beaufort Sea (Fig. 2b). Precipitation magnitudes from the reanalyses (excluding CFSR) are much lower than for the other buoys, hovering around $5 \mathrm{~mm}^{\text {day }}{ }^{-1}$ (Fig. 11b). None of the reanalyses produce snowfall events coincident with buoy snowfall events after 11 December (day 345) at this location, thus the increases in snow depth could have been due to drifting/ blowing snow, since blowing snow is most common and relatively little snowfall occurs in the Beaufort Sea in the winter months (Radionov et al. 1997). Another possibility is that snowfall events did occur at this buoy, but the reanalyses did not accurately simulate the precipitation events.

\section{g. Snow depth equivalent}

To gain a better understanding of how well the magnitude of the reanalyses' precipitation events compare with the buoys, we convert precipitation greater than $1 \mathrm{~mm}^{\text {day }}{ }^{-1}$ to snow depth following Kwok and Cunningham (2008). At each daily location of the 57 IMB buoys, snow depths were computed using the reanalyses' precipitation rates and the climatological snow density from Warren et al. (1999). Daily density values were linearly interpolated from the monthly means. Each reanalysis's snow depth was initialized to the initial snow depth of the buoy. If two consecutive days of above-freezing air temperatures occurred, the snow depth was set to $0 \mathrm{~m}$ to approximate melt.

The median differences between the daily reanalysisderived snow depths at the 57 buoy tracks and the buoy snow depths are shown as box-and-whisker plots in Fig. 12a. The central red mark on the box is the median difference, and the bottom and top edges of the box represent the 25 th and 75 th percentiles, respectively. The whiskers extend to the most extreme data points not considered outliers. From this comparison, it was found that MERRA $(-0.3 \pm 0.2 \mathrm{~cm}), \operatorname{NCEPR} 2(3.0 \pm 0.2 \mathrm{~cm})$, and ERA-Interim $(3.9 \pm 0.2 \mathrm{~cm})$ exhibited the smallest median difference (and standard deviation from the difference) in snow depth compared to the observations. NCEP R1 produced the smallest difference; however, this may be due to the influence of random noise in the data, because of its well-known ringing issue (Lindsay et al. 2014). ASRv1 and JRA-55 produced median differences of $6.1 \pm 0.2 \mathrm{~cm}$ and $7.7 \pm 0.2 \mathrm{~cm}$, respectively. CFSR $(18.7 \pm 0.4 \mathrm{~cm})$ and MERRA-2 $(8.7 \pm 0.2 \mathrm{~cm})$, the reanalyses with a generally high precipitation bias, showed the largest difference and spread from the buoys. It is important to note, however, that the location of the majority of the buoys do not represent the whole Arctic.

Figures $12 \mathrm{~b}$ and $12 \mathrm{c}$ show the time series comparisons of the daily computed reanalyses' snow depths without 
a)

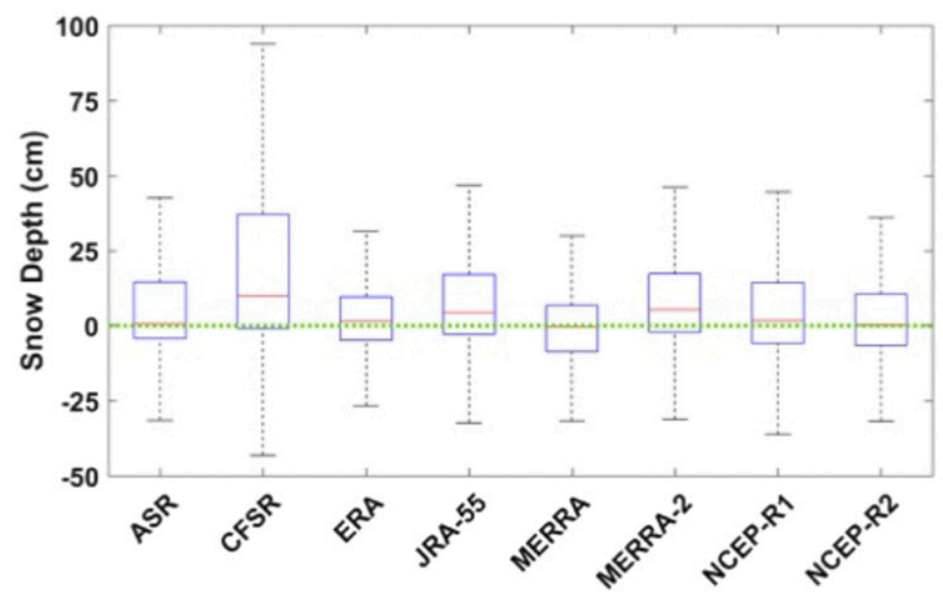

b)

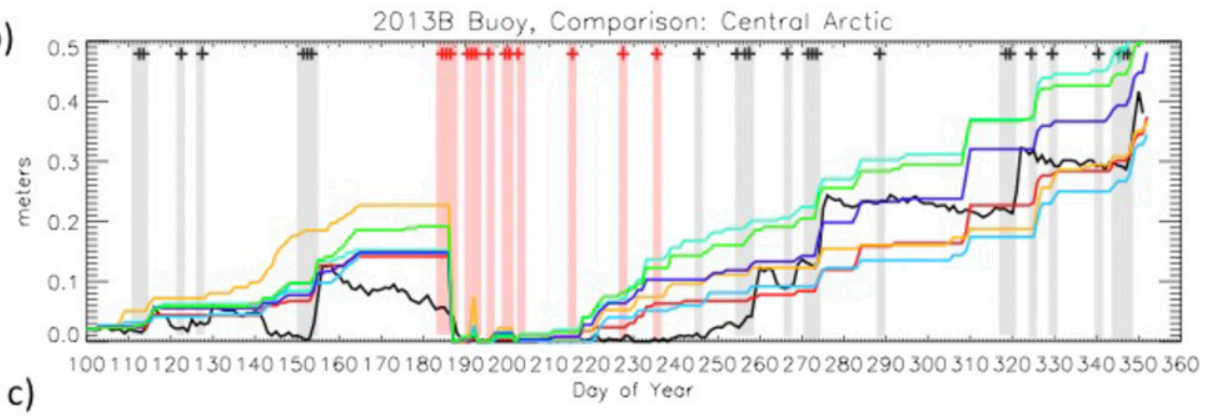

\begin{tabular}{|l|}
\hline \multicolumn{1}{|c|}{ Legend } \\
\hline IRA-SS \\
ERA-Interim \\
NCEP R1 \\
NCEP R2 \\
ASR \\
MERRA \\
MERRA2 \\
+ Snow Event \\
+ Temp. $>0^{\circ} \mathrm{C}$ \\
\hline Buoy \\
\hline
\end{tabular}

20111 Buoy, Comparison: Beaufort Seo

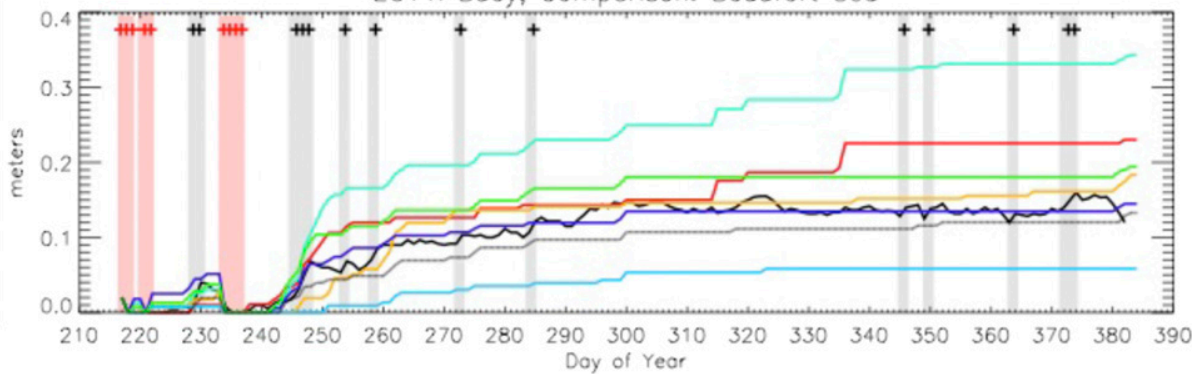

FIG. 12. (a) A box-and-whisker plot showing the differences of daily snow depths from 57 IMB buoys and reanalysis-constructed snow depths for 2000-15. Note that not all reanalyses cover the $2000-15$ period (e.g., ASRv1). As described in the text, the central red mark on the box is the median, and the bottom and top edges of the box represent the 25th and 75th percentiles, respectively. The whiskers extend to the most extreme data points not considered outliers. The dashed green line marks zero difference. (b) The 2013B buoy (all reanalyses except ASRv1 and CFSR). (c) The 2011I buoy (all reanalyses except CFSR). IMB buoy (track shown in Fig. 2b) snow depth $(\mathrm{m})$ shown by the black line. Each colored line represents the daily snow depth calculated with the specific reanalysis precipitation rate (not including $\mathrm{TP}<1 \mathrm{~mm} \mathrm{day}^{-1}$ ) at the location of the buoy. The black + marks and gray shaded boxes represent snowfall events. The red + marks and red shaded boxes represent times where the buoy recorded air temperatures above $0^{\circ} \mathrm{C}$. In (c), note that the line for ASRv1 is dashed.

TP (colored lines) with the 2013B and 2011I buoy snow depths (black lines). Although this is a simplified method excluding snow processes, there is good agreement between the reanalyses' snow depths and buoy snow depths. ASRv1 and ERA-Interim produce similar magnitudes of snow depth compared with what the 2011I IMB buoy recorded toward the end of the buoy's deployment (Fig. 12c). The 2013B snow depth is more difficult to reconstruct from the reanalyses' precipitation because of the inclusion of the entire summer months when melting and freezing conditions occur intermittently, highlighting the difficulty in modeling snow depths during this season. However, on 20 July (day 201), the reanalyses' snow depths begin to exhibit a realistic, seasonal buildup of the snowpack relative to the observations (Fig. 12b). NCEP R1, NCEP R2, and 
MERRA all produce similar snow depths to the buoy at the end of the deployment. However, Fig. 12b also demonstrates that modeling snowfall during these cyclonic events is highly variable.

\section{Discussion}

Precipitation is a predicted variable dependent upon not only how observations are assimilated into the reanalysis system but how the reanalysis reproduces many other derived variables and complex physical processes, such as surface and boundary layer processes, clouds and cloud microphysics and processes therein. They also must mimic these complex processes in a simplified way (for processing power/time) with many assumptions, and on a global scale. Many of these unique processes in the Arctic are not well understood or captured correctly by the reanalyses. For example, how each reanalysis treats sea ice cover influences the representation of boundary layer processes, surface energy, and moisture fluxes and the resulting temperature and moisture distribution in the overlying atmosphere. These differences can ultimately affect the precipitation field and may be a factor in how precipitation varies across the reanalyses.

Across all reanalyses, cloud processes are driven/ initiated by the humidity and temperature of the air. The presence of clouds, synoptic-scale vertical motions, and finally precipitation are dependent on the accuracy of these variables and how realistically they are produced. Biases in temperature and humidity profiles-unique to each reanalysis-are present in the Arctic (Jakobson et al. 2012; Tjernström et al. 2012; Lindsay et al. 2014) and may also contribute to differences found in precipitation fields. Reanalyses tend to reproduce the daily variability well when compared with observations (Lindsay et al. 2014), but their magnitudes tend to be biased. These biases could explain why reanalyses show similar interannual variability and widely different magnitudes of precipitation.

In a natural setting, clouds (whether they be liquid, ice, or mixed phase) are produced when air parcels are moved via synoptic-scale vertical motions above the saturation level (dependent on the temperature and humidity of the parcel). Rainfall, for example, is produced if there are sufficient cloud condensation nuclei available to produce a range of droplet sizes and if there is sufficient vertical motion within the cloud, which allows for the droplets to collide and coalesce, forming larger droplets. Precipitation efficiency is influenced by heterogeneity in the distribution and phase of the cloud condensate (e.g., Wallace and Hobbs 2006). The phase of the precipitation may also change as it falls through the air toward the ground. All of these complex interactions contribute to the magnitude, frequency, and phase of the precipitation produced by reanalyses.

Over the time period covered by reanalyses, there are no direct measurements of these complex processes, and therefore must be modeled in a simplified manner with many assumptions. Cloud microphysics schemes that produce modeled precipitation thus differ in the assumptions of particle size distribution and shape, mass diameter, particle fall speed, and other processes such as collision and coalescence (Han et al. 2013). More specifically, bulk parameterizations simulate the coalescence of the particles by assuming a particle size distribution (e.g., one-moment scheme) and the mass-mixing ratio (for two-moment schemes; improving the representation of the particle size distribution) in order to predict other bulk quantities of this distribution (Morrison et al. 2009). The microphysics are also controlled by the phase of the clouds and the difficulty in predicting these clouds phases, especially in the Arctic, thus adding to the complexity in simulating precipitation (Morrison and Pinto 2006). Since each reanalysis utilizes a different cloud microphysics scheme (Table 1), we believe this largely explains the myriad of differences seen across the precipitation products.

Previous studies focused on the midlatitudes and tropics have shown that most reanalyses tend to underestimate the magnitude of heavy precipitation events but produce precipitation at low rates (e.g., TP) nearly every day, and because of this, they tend to have reasonable annual precipitation amounts (Chen et al. 1996; Osborn and Hulme 1998; Dai et al. 1999; Trenberth et al. 2003; Dai and Trenberth 2004). Although the Arctic environment is very different compared to these regions, the problems with modeling precipitation using simplified assumptions to model complex processes is universal. Precipitation in the Arctic is not often produced by convection; however, it is apparent that the cloud and microphysical schemes are producing excess TP almost daily.

The precipitation phase is also an important factor, because it will alter the physical and reflective characteristics of the snowpack. Our comparisons with the buoys have shown that during seasonal transitions (spring to summer and summer to fall), when air temperatures are near the freezing point and humidity is more highly variable, the phase of the precipitation is also highly variable. The variability in precipitation phase could be attributed to the known temperature and humidity near the surface and profile biases unique to each reanalysis (Jakobson et al. 2012), which are exacerbated when the buoy temperature is hovering around $0^{\circ} \mathrm{C}$. For example, if snow falls through a layer of warm air near the surface and melts, it will become rain when it 
reaches the surface. In winter, when temperatures are much colder and humidity is lower, the phase of these precipitation events might be easier to predict. Some reanalyses do not differentiate between the precipitation phase, and it is likely that they treat these processes in a more simplified manner. Improving the accuracy of these atmospheric variables would improve the accuracy of the phase of the precipitation as well.

The complexities of the sea ice surface, boundary layer processes, cloud and microphysics schemes, their assumptions, and the resulting precipitation produced pose a difficult challenge to those trying to diagnose which processes are responsible for the differences in precipitation in the Arctic. Future work will need to be done to pinpoint and improve upon these and other processes; however, this is beyond the scope of this study.

\section{Conclusions}

Precipitation over the Arctic Ocean and peripheral seas has been notoriously uncertain in reanalyses because of a lack of understanding of the basic cloud properties and precipitation processes and a lack of validation datasets due to difficulties associated with collecting in situ observations in the harsh environment present in polar environments. The eight reanalyses compared here have shown a large spread in the magnitude and frequency of precipitation, whether it be snowfall, rainfall, or trace precipitation. One promising result is that the reanalyses show similar patterns of interannual variability in the magnitude and frequency of precipitation. The reanalyses do not show any increases in the amount of total precipitation in the new Arctic, but show decreases in snowfall, compensated by an increase in rainfall amount and frequency. This could be due to a warming Arctic climate and is especially true in the North Atlantic regions, warranting a more detailed look into the phase of precipitation associated with cyclones.

ASRv1 may be seen as a unique product in this comparison as it is a regional reanalysis that utilizes lateral boundary conditions supplied by a global reanalysis. As with other reanalyses, ASRv1 assimilates observations, but it is specifically targeted for the Arctic conditions with a higher spatial resolution and physical parameterizations that are thought to be more relevant to the Arctic. When comparing ASRv1 to the other global reanalyses, ASRv1 precipitation (without TP) totals agree with those measured by the IMB buoys as do the global reanalyses, except for CFSR and MERRA-2, which are excessive. When total precipitation is considered, ASRv1 appears to be biased low but the magnitude is uncertain because of the shortage of observations. ASRv1 total precipitation is likely to be more accurate in and adjacent to regions of complex terrain where high spatial resolution is an advantage, however. Snow-rain partitioning is quite different between the reanalyses and requires further research to resolve. Thus the use of ASRv1 over the global reanalyses depends on the application.

The reasons for the large spread in precipitation between reanalyses is likely because the magnitude and frequency of the precipitation is driven by differing boundary layer processes, cloud and microphysical schemes employed, and their assumptions therein. Comparisons with the IMB buoys have provided valuable insights in that the majority of the reanalyses pick up on the precipitation events that the buoys record ( $>70 \%$ of the time); however, the spread in the magnitude of precipitation during these events can vary by up to $20 \mathrm{~mm} \mathrm{day}^{-1}$ across products, which demonstrates that they can predict the precipitation events reasonably, but not the magnitude. When converting daily precipitation rates into equivalent snow depths for 57 buoys, MERRA, NCEP R2, and ERA-Interim produced the closest results to those from the buoys. We do not recommend the use of NCEP R1 (because of the ringing), as well as CFSR or MERRA-2, because of the large differences with the buoys and the other reanalyses products.

We have shown that reanalyses have many difficulties producing accurate precipitation in the Arctic. This creates multiple issues when modeling sea ice thickness. For instance, if a reanalysis produces too much or too little snowfall or rainfall, then the depth of the snowpack, albedo, and insulating properties will all be altered and affect the snowpack and underlying sea ice throughout the year. Hence, the amount of snow on top of the Arctic sea ice is a determining factor in the growth and decay of Arctic sea ice (Maykut and Untersteiner 1971). Inaccurate snow depths will bias sea ice thickness from freeboard altimetry measurements from those like ICESat-2 and CryoSat-2 (Giles et al. 2008). For example, a 20 -cm error in snow depth leads to $\sim 1$-m error in sea ice thickness, which, again, stresses the importance of the quality and quantity of the reanalyses' precipitation forcing used in snowpack modeling for altimetry freeboard and ice thickness estimates.

This analysis highlights the discrepancies between widely used reanalyses' precipitation products in the Arctic, specifically the magnitude, frequency, and phase (or lack thereof, depending on the reanalysis used) of this precipitation. Precipitation is a crucial variable for local and global water and energy budgets as well as for those modeling the snowpack on sea ice. Future efforts 
are therefore crucial to improve representations of complex processes in the Arctic atmosphere, including boundary layer processes, vertical motions, cloud type, and cloud microphysics, that all drive precipitation in the Arctic.

Acknowledgments. The ASRv1, NCEP R1, and NCEP R2 were obtained from the NCAR Research Data Archive. CFSR fields were obtained from the National Operational Model Archive and Distribution System (NOMADS) at the U.S. National Climatic Data Center. ERA-Interim fields were obtained from the ECMWF Meteorological Archival and Retrieval System (MARS). JRA-55 fields were obtained from the Japan Meteorological Agency Climate Prediction Division, Global Environment and Marine Department. MERRA and MERRA-2 were obtained from the NASA Goddard Earth Sciences Data and Information Services Center (GES-DISC). The work of L. Boisvert, M. Webster, A. Petty, and T. Markus was funded by the NASA-ESA Snow On Sea Ice (NESOSI) project. R. Cullather is funded through the NASA Modeling, Analysis, and Prediction Program under Grant NNX17AE79A. D. Bromwich is funded through the Office of Naval Research Grant N00014-18-1-2361. Contribution 1569 of Byrd Polar and Climate Research Center.

\section{REFERENCES}

Adam, J. C., and D. P. Lettenmaier, 2003: Adjustment of global gridded precipitation for systematic bias. J. Geophys. Res., 108, 4257, https://doi.org/10.1029/2002JD002499.

Bacmeister, J. T., M. J. Suarez, and F. R. Robertson, 2006: Rain reevaporation, boundary layer-convection interactions, and Pacific rainfall patterns in the AGCM. J. Atmos. Sci., 63, 33833403, https://doi.org/10.1175/JAS3791.1.

Bintanja, R., and F. M. Selten, 2014: Future increases in Arctic precipitation linked to local evaporation and sea-ice retreat. Nature, 509, 479-482, https://doi.org/10.1038/nature13259.

— Nat. Climate Change, 7, 263-267, https://doi.org/10.1038/ nclimate3240.

Blanchard-Wrigglesworth, E., M. A. Webster, S. L. Farrell, and C. M. Bitz, 2018: Reconstruction of snow on Arctic sea ice. J. Geophys. Res. Oceans, 123, 3588-3602, https://doi.org/ 10.1002/2017JC013364.

Boisvert, L. N., and J. C. Stroeve, 2015: The Arctic is becoming warmer and wetter as revealed by the Atmospheric Infrared Sounder. Geophys. Res. Lett., 42, 4439-4446, https://doi.org/ 10.1002/2015GL063775.

- , D. L. Wu, and C.-L. Shie, 2015: Increasing evaporation amounts seen in the Arctic between 2003 and 2013 from AIRS data. J. Geophys. Res. Atmos., 120, 6865-6881, https://doi.org/ 10.1002/2015JD023258.

Bosilovich, M. G., F. R. Robertson, and J. Chen, 2011: Global energy and water budgets in MERRA. J. Climate, 24, 57215739, https://doi.org/10.1175/2011JCLI4175.1.
Bromwich, D. H., A. B. Wilson, L.-S. Bai, G. W. K. Moore, and P. Bauer, 2016: A comparison of the regional Arctic System Reanalysis and the global ERA-Interim reanalysis for the Arctic. Quart.J. Roy. Meteor. Soc., 142, 644-658, https://doi.org/ 10.1002/qj.2527.

Chen, M., R. E. Dickinson, X. Zeng, and A. N. Hahmann, 1996: Comparison of precipitation observed over the continental United States to that simulated by a climate model. J. Climate, $\mathbf{9}$, 2233-2249, https://doi.org/10.1175/1520-0442(1996)009<2233: COPOOT $>2.0 . \mathrm{CO} ; 2$.

Colony, R., V. Radionov, and F. J. Tanis, 1998: Measurements of precipitation and snow pack at Russian North Pole drifting stations. Polar Rec., 34, 3-14, https://doi.org/10.1017/ S0032247400014923.

Comiso, J. C., C. L. Parkinson, R. Gersten, and L. Stock, 2008: Accelerated decline in the Arctic sea ice cover. Geophys. Res. Lett., 35, L01703, https://doi.org/10.1029/2007GL031972.

Cullather, R. I., and M. G. Bosilovich, 2011: The moisture budget of the polar atmosphere in MERRA. J. Climate, 24, 28612879, https://doi.org/10.1175/2010JCLI4090.1.

- D. H. Bromwich, and M. C. Serreze, 2000: The atmospheric hydrologic cycle over the Arctic Basin from reanalyses. Part I: Comparisons with observations and previous studies. J. Climate, 13, 923-937, https://doi.org/10.1175/1520-0442(2000)013<0923: TAHCOT $>2.0 . \mathrm{CO} ; 2$.

- T. M. Hamill, D. Bromwich, X. Wu, and P. Taylor, 2016: Systematic Improvements of Reanalyses in the Arctic (SIRTA): A white paper (draft). Interagency Arctic Research Policy Committee Rep., 46 pp.

Dai, A., 2006: Precipitation characteristics in eighteen coupled climate models. J. Climate, 19, 4605-4630, https://doi.org/ 10.1175/JCLI3884.1.

— , and K. E. Trenberth, 2004: The diurnal cycle and its depiction in the community climate system model. J. Climate, 17, 930-951, https://doi.org/10.1175/1520-0442(2004)017<0930: TDCAID $>2.0 . \mathrm{CO} ; 2$.

— , F. Giorgi, and K. E. Trenberth, 1999: Observed and modelsimulated precipitation diurnal cycles over the contiguous United States. J. Geophys. Res., 104, 6377-6402, https://doi.org/ 10.1029/98JD02720.

Dee, D. P., and Coauthors, 2011: The ERA-Interim reanalysis: Configuration and performance of the data assimilation system. Quart. J. Roy. Meteor. Soc., 137, 553-597, https://doi.org/ 10.1002/qj.828.

Gelaro, R., and Coauthors, 2017: The Modern-Era Retrospective Analysis for Research and Applications, version 2 (MERRA-2). J. Climate, 30, 5419-5454, https://doi.org/10.1175/JCLI-D-16-0758.1.

Giles, K. A., S. W. Laxon, and A. L. Ridout, 2008: Circumpolar thinning of Arctic sea ice following the 2007 record ice extent minimum. Geophys. Res. Lett., 35, L22502, https://doi.org/ 10.1029/2008GL035710.

Goodison, B. E., E. Elomaa, V. Golubev, T. Gunther, and B. Sevruk, 1994: WMO solid precipitation measurement intercomparison: Preliminary results. WMO/TD-588, 82 pp.

- P. Y. T. Louie, and D. Yang, 1998: WMO solid precipitation intercomparison: Final report. WMO/TD-872, 212 pp.

Grumbine, R. W., 1996: Automated passive microwave sea ice concentration analysis at NCEP OMB. NOAA Tech. Note 120, 13 pp.

Han, M., S. A. Braun, T. Matsui, and C. R. Williams, 2013: Evaluation of cloud microphysics schemes in simulations of a winter storm using radar and radiometer measurements. J. Geophys. Res. Atmos., 118, 1401-1419, https://doi.org/10.1002/ jgrd.50115. 
Hibler, W. D., and J. Zhang, 1995: On the effect of sea-ice dynamics on oceanic thermohaline circulation. Ann. Glaciol., 21, 361368, https://doi.org/10.1017/S0260305500016074.

Ishii, M., A. Shouji, S. Sugimoto, and T. Matsumoto, 2005: Objective analyses of sea-surface temperature and marine meteorological variables for the 20th century using ICOADS and the Kobe Collection. Int. J. Climatol., 25, 865-879, https://doi.org/ 10.1002/joc.1169.

Jakobson, E., T. Vihma, T. Palo, L. Jakobson, H. Keernik, and J. Jaagus, 2012: Validation of atmospheric reanalyses over the central Arctic Ocean. Geophys. Res. Lett., 39, L10802, https:// doi.org/10.1029/2012GL051591.

Kalnay, E., and Coauthors, 1996: The NCEP/NCAR 40-Year Reanalysis Project. Bull. Amer. Meteor. Soc., 77, 437-471, https:// doi.org/10.1175/1520-0477(1996)077<0437:TNYRP>2.0.CO;2.

Kanamitsu, M., W. Ebisuzaki, J. Woollen, S.-K. Yang, J. J. Hnilo, M. Fiorino, and G. L. Potter, 2002: NCEP-DOE AMIP-II Reanalysis (R-2). Bull. Amer. Meteor. Soc., 83, 1631-1644, https://doi.org/10.1175/BAMS-83-11-1631.

Kattsov, V. M., J. E. Walsh, W. L. Chapman, V. A. Govorkova, T. V. Pavlova, and X. Zhang, 2007: Simulation and projection of Arctic freshwater budget components by the IPCC AR4 global climate models. J. Hydrometeor., 8, 571-589, https://doi.org/ 10.1175/JHM575.1.

Kobayashi, S., and Coauthors, 2015: The JRA-55 reanalysis: General specifications and basic characteristics. J. Meteor Soc. Japan, 93, 5-48, https://doi.org/10.2151/jmsj.2015-001.

Kurtz, N. T., and S. L. Farrell, 2011: Large-scale surveys of snow depth on Arctic sea ice from Operation IceBridge. Geophys. Res. Lett., 38, L20505, https://doi.org/10.1029/2011GL049216.

Kwok, R., and G. F. Cunningham, 2008: ICESat over Arctic sea ice: Estimation of snow depth and ice thickness. J. Geophys. Res., 113, C08010, https://doi.org/10.1029/2008JC004753.

$\longrightarrow,-$ - M. Wensnahan, I. Rigor, H. J. Zwally, and D. Yi, 2009: Thinning and volume loss of the Arctic Ocean sea ice cover: 2003-2008. J. Geophys. Res., 114, C07005, https://doi.org/ 10.1029/2009JC005312.

Lindsay, R., and A. Schweiger, 2015: Arctic sea ice thickness loss determined using subsurface, aircraft, and satellite observations. Cryosphere, 9, 269-283, https://doi.org/10.5194/tc-9-269-2015.

_-, M. Wensnahan, A. Schweiger, and J. Zhang, 2014: Evaluation of seven different atmospheric reanalysis products in the Arctic. J. Climate, 27, 2588-2606, https://doi.org/10.1175/ JCLI-D-13-00014.1.

Lique, C., M. M. Holland, Y. B. Dibike, D. M. Lawrence, and J. A. Screen, 2016: Modeling the Arctic freshwater system and its integration in the global system: Lessons learned and future challenges. J. Geophys. Res. Biogeosci., 121, 540-566, https:// doi.org/10.1002/2015JG003120.

Maksym, T., and T. Markus, 2008: Antarctic sea ice thickness and snow-to-ice conversion from atmospheric reanalysis and passive microwave snow depth. J. Geophys. Res., 113, C02S12, https://doi.org/10.1029/2006JC004085.

Markus, T., and Coauthors, 2017: The Ice, Cloud and Land Elevation Satellite-2 (ICESat-2): Science requirements, concept, and implementation. Remote Sens. Environ., 190, 260-273, https://doi.org/10.1016/j.rse.2016.12.029.

Maslanik, J., and J. Stroeve, 1990: DMSP SSM/I brightness temperature grids for the polar regions on CD-ROM: User's guide. NSIDC, CD-ROM.

Maykut, G. A., and N. Untersteiner, 1971: Some results from a time-dependent, thermodynamic model of sea ice. J. Geophys. Res., 76, 1550-1575, https://doi.org/10.1029/JC076i006p01550.
Molod, A., 2012: Constraints on the profiles of total water PDF in AGCMs from AIRS and a high-resolution model. J. Climate, 25, 8341-8352, https://doi.org/10.1175/JCLI-D-11-00412.1.

Moorthi, S., H.-L. Pan, and P. Caplan, 2001: Changes to the 2001 NCEP operational MRF/AVN global analysis/forecast system. NWS Tech. Procedures Bull. 484, 14 pp.

Morrison, H., and J. O. Pinto, 2006: Intercomparison of bulk cloud microphysics schemes in mesoscale simulations of springtime Arctic mixed-phase stratiform clouds. Mon. Wea. Rev., 134, 1880-1900, https://doi.org/10.1175/MWR3154.1.

, G. Thompson, and V. Tatarskii, 2009: Impact of cloud microphysics on the development of trailing stratiform precipitation in a simulated squall line: Comparison of one- and two-moment schemes. Mon. Wea. Rev., 137, 991-1007, https:// doi.org/10.1175/2008MWR2556.1.

Osborn, T. J., and M. Hulme, 1998: Evaluation of the European daily precipitation characteristics from the atmospheric model intercomparison project. Int. J. Climatol., 18, 505522, https://doi.org/10.1002/(SICI)1097-0088(199804)18: $5<505:$ :AID-JOC263>3.0.CO;2-7.

Parkinson, C. L., 2014: Spatially mapped reductions in the length of the Arctic sea ice season. Geophys. Res. Lett., 41, 4316-4322, https://doi.org/10.1002/2014GL060434.

Perovich, D. K., T. C. Grenfell, B. Light, and P. V. Hobbs, 2002: Seasonal evolution of the albedo of multiyear Arctic sea ice. $J$. Geophys. Res., 107, 8044, https://doi.org/10.1029/2000JC000438.

—, J. Richter-Menge, B. Elder, T. Arbetter, K. Claffey, and C. Polashenski, 2017: Observing and understanding climate change: Monitoring the mass balance, motion, and thickness of Arctic sea ice. Cold Regions Research and Engineering Laboratory, accessed 20 January 2017, http://imb-crrel-dartmouth.org/ imb.crrel/buoysum.htm.

Radionov, V. F., N. N. Bryazgin, and E. I. Alexandrov, 1997: The snow cover of the Arctic Basin. Applied Physics Laboratory Tech. Rep. APL-UW TR 9701, 95 pp.

Rawlins, M. A., and Coauthors, 2010: Analysis of the Arctic system for freshwater cycle intensification: Observations and expectations. J. Climate, 23, 5715-5737, https://doi.org/10.1175/ 2010JCLI3421.1.

Reynolds, R. W., N. A. Rayner, T. M. Smith, D. C. Stokes, and W. Wang, 2002: An improved in situ and satellite SST analysis for climate. J. Climate, 15, 1609-1625, https://doi.org/10.1175/ 1520-0442(2002)015<1609:AIISAS > 2.0.CO;2.

—, T. M. Smith, C. Liu, D. B. Chelton, K. S. Casey, and M. G. Schlax, 2007: Daily high-resolution-blended analyses for sea surface temperature. J. Climate, 20, 5473-5496, https://doi.org/ 10.1175/2007JCLI1824.1.

Rienecker, M. M., and Coauthors, 2011: MERRA: NASA's Modern-Era Retrospective Analysis for Research and Applications. J. Climate, 24, 3624-3648, https://doi.org/10.1175/ JCLI-D-11-00015.1.

Rogers, A. N., D. H. Bromwich, E. N. Sinclair, and R. I. Cullather, 2001: The atmospheric hydrologic cycle over the Arctic Basin from reanalyses. Part II: Interannual variability. J. Climate, 14, 2414-2429, https://doi.org/10.1175/1520-0442(2001)014<2414: TAHCOT $>2.0 . \mathrm{CO} ; 2$.

Saha, S., and Coauthors, 2010: The NCEP Climate Forecast System Reanalysis. Bull. Amer. Meteor. Soc., 91, 1015-1058, https:// doi.org/10.1175/2010BAMS3001.1.

Serreze, M. C., and C. M. Hurst, 2000: Representation of mean Arctic precipitation from NCEP-NCAR and ERA reanalyses. J. Climate, 13, 182-201, https://doi.org/10.1175/ 1520-0442(2000)013<0182:ROMAPF $>2.0 . C O ; 2$. 
, and A. P. Barrett, 2008: The summer cyclone maximum over the central Arctic Ocean. J. Climate, 21, 1048-1065, https://doi.org/ 10.1175/2007JCLI1810.1.

— J. E. Box, R. G. Barry, and J. E. Walsh, 1993: Characteristics of Arctic synoptic activity, 1952-1989. Meteor. Atmos. Phys., 51, 147-164, https://doi.org/10.1007/BF01030491.

— R. G. Barry, and J. E. Walsh, 1995: Atmospheric water vapor characteristics at $70^{\circ}$ N. J. Climate, 8, 719-731, https://doi.org/ 10.1175/1520-0442(1995)008<0719:AWVCA > 2.0.CO;2.

$\longrightarrow$ A. P. Barrett, and F. Lo, 2005: Northern high-latitude precipitation as depicted by atmospheric reanalyses and satellite retrievals. Mon. Wea. Rev., 133, 3407-3430, https://doi.org/ 10.1175/MWR3047.1.

Sevruk, B., 1982: Methods of correction for systematic error in point precipitation measurement for operational use. Operational Hydrology Rep. 589, WMO, 91 pp.

Simmonds, I., C. Burke, and K. Keay, 2008: Arctic climate change as manifest in cyclone behavior. J. Climate, 21, 5777-5796, https://doi.org/10.1175/2008JCLI2366.1.

Smith, R. N. B., 1990: A scheme for predicting layer clouds and their water content in a general circulation model. Quart. J. Roy. Meteor. Soc., 116, 435-460, https://doi.org/10.1002/ qj. 49711649210 .

Sturm, M., J. Holmgren, and D. K. Perovich, 2002: Winter snow cover on the sea ice of the Arctic Ocean at the Surface Heat Budget of the Arctic Ocean (SHEBA): Temporal evolution and spatial variability. J. Geophys. Res., 107, 8047, https://doi.org/ 10.1029/2000JC000400.

Sundqvist, H., 1998: Parameterization of condensation and associated clouds in models for weather prediction and general simulation. Physically-Based Modelling and Simulation of Climate and Climatic Change: Part 1, M. E. Schlesinger, Ed., D. Reidel, 433-461.

Tao, W.-K., and J. Simpson, 1993: The Goddard Cumulus Ensemble Model. Part I: Model description. Terr. Atmos. Oceanic Sci., 4, 19-54, https://doi.org/10.3319/TAO.1993.4.1.35(A).

— - and Coauthors, 2003: Microphysics, radiation and surface processes in the Goddard Cumulus Ensemble (GCE) Model. Meteor. Atmos. Phys., 82, 97-137, https://doi.org/10.1007/ s00703-001-0594-7.

Tiedtke, M., 1993: Representation of clouds in large-scale models. Mon. Wea. Rev., 121, 3040-3061, https://doi.org/10.1175/ 1520-0493(1993)121<3040:ROCILS > 2.0.CO;2.

Tjernström, M., and Coauthor, 2012: Meteorological conditions in the central Arctic summer during the Arctic Summer Cloud Ocean Study (ASCOS). Atmos. Chem. Phys., 12, 6863-6889, https://doi.org/10.5194/acp-12-6863-2012.
Tompkins, A. M., 2002: A prognostic parameterization for the subgrid-scale variability of water vapor and clouds in largescale models and its use to diagnose cloud cover. J. Atmos. Sci., 59, 1917-1942, https://doi.org/10.1175/1520-0469(2002)059<1917: APPFTS $>2.0 . \mathrm{CO} ; 2$.

Trenberth, K. E., A. Dai, R. M. Rasmussen, and D. B. Parsons, 2003: The changing character of precipitation. Bull. Amer. Meteor. Soc., 84, 1205-1218, https://doi.org/10.1175/ BAMS-84-9-1205.

—, T. Koike, and K. Onogi, 2008: Progress and prospects for reanalysis for weather and climate. Eos, Trans. Amer. Geophys. Union, 89, 234-235, https://doi.org/10.1029/2008EO260002.

_ _ J. T. Fasullo, and J. Mackaro, 2011: Atmospheric moisture transports from ocean to land and global energy flows in reanalyses. J. Climate, 24, 4907-4924, https://doi.org/10.1175/ 2011JCLI4171.1.

Vihma, T., 2014: Effects of Arctic sea ice decline on weather and climate: A review. Surv. Geophys., 35, 1175-1214, https://doi.org/ 10.1007/s10712-014-9284-0.

Wallace, J. M., and P. V. Hobbs, 2006: Atmospheric Science: An Introductory Survey. 2nd ed. Elsevier, 504 pp.

Walsh, J. E., V. Kattsov, D. Portis, and V. Meleshko, 1998: Arctic precipitation and evaporation: Model results and observational estimates. J. Climate, 11, 72-87, https://doi.org/10.1175/ 1520-0442(1998)011<0072:APAEMR>2.0.CO;2.

Warren, S. G., I. G. Rigor, N. Untersteiner, V. F. Radionov, N. N Bryazgin, Y. I. Aleksandrov, and R. Colony, 1999: Snow depth on Arctic sea ice. J. Climate, 12, 1814-1829, https://doi.org/ 10.1175/1520-0442(1999)012<1814:SDOASI $>2.0$.CO;2.

Webster, M. A., I. G. Rigor, S. V. Nghiem, N. T. Kurtz, S. L. Farrell, D. K. Perovich, and M. Sturm, 2014: Interdecadal changes in snow depth on Arctic sea ice. J. Geophys. Res. Oceans, 119 , 5395-5406, https://doi.org/10.1002/2014JC009985.

Wingham, D. J., and Coauthors, 2006: CryoSat: A mission to determine the fluctuations in Earth's land and marine ice fields. Adv. Space Res., 37, 841-871, https://doi.org/10.1016/ j.asr.2005.07.027.

Yang, D., 1999: An improved precipitation climatology for the Arctic Ocean. Geophys. Res. Lett., 26, 1625-1628, https://doi.org/ 10.1029/1999GL900311.

— gauge: Result of WMO intercomparison. Hydrol. Processes, $\mathbf{9}$, 877-895, https://doi.org/10.1002/hyp.3360090805.

Zhang, X., J. E. Walsh, J. Zhang, U. S. Bhatt, and M. Ikeda, 2004: Climatology and interannual variability of Arctic cyclone activity: 1948-2002. J. Climate, 17, 2300-2317, https://doi.org/ 10.1175/1520-0442(2004)017<2300:CAIVOA >2.0.CO;2. 